\title{
Article \\ Mapping Blue and Red Color-Coated Steel Sheet Roof Buildings over China Using Sentinel-2A/B MSIL2A Images
}

\author{
Alim Samat ${ }^{1,2,3, * \mathbb{C}}$, Paolo Gamba ${ }^{4}$, Wei Wang ${ }^{1,2,3(\mathbb{C}}$, Jieqiong Luo ${ }^{5}$, Erzhu Li ${ }^{6}$, Sicong Liu ${ }^{7} \mathbb{C}$, Peijun Du 8 (1) \\ and Jilili Abuduwaili 1,2,3 (D)
}

1 State Key Laboratory of Desert and Oasis Ecology, Xinjiang Institute of Ecology and Geography, Chinese Academy of Sciences, Urumqi 830011, China; wangwei177@mails.ucas.ac.cn (W.W.); jili1@ms.xjb.ac.cn (J.A.)

2 Research Center for Ecology and Environment of Central Asia, Chinese Academy of Sciences, Urumqi 830011, China

3 University of Chinese Academy of Sciences, Beijing 100049, China

4 Department of Electrical, Computer and Biomedical Engineering, University of Pavia, 27100 Pavia, Italy; paolo.gamba@unipv.it

5 School of Transportation and Civil Engineering, Nantong University, Nantong 226007, China; luojq@ntu.edu.cn

6 Department of Geographical Information Science, Jiangsu Normal University, Xuzhou 221008, China; liezrs2008@jsnu.edu.cn

7 College of Surveying and Geoinformatics, Tongji University, Shanghai 200070, China; sicong.liu@tongji.edu.cn

8 School of Geography and Ocean Science, Nanjing University, Nanjing 210093, China; peijun@nju.edu.cn

* Correspondence: alim_smt@ms.xjb.ac.cn

Citation: Samat, A.; Gamba, P.; Wang, W.; Luo, J.; Li, E.; Liu, S.; Du, P.; Abuduwaili, J. Mapping Blue and Red Color-Coated Steel Sheet Roof Buildings over China Using Sentinel-2A/B MSIL2A Images. Remote Sens. 2022, 14, 230. https:// doi.org/10.3390/rs14010230

Academic Editor: Koreen Millard

Received: 17 November 2021

Accepted: 30 December 2021

Published: 5 January 2022

Publisher's Note: MDPI stays neutral with regard to jurisdictional claims in published maps and institutional affiliations.

Copyright: (C) 2022 by the authors. Licensee MDPI, Basel, Switzerland. This article is an open access article distributed under the terms and conditions of the Creative Commons Attribution (CC BY) license (https:// creativecommons.org/licenses/by/ $4.0 /)$.

\begin{abstract}
Accurate and efficiently updated information on color-coated steel sheet (CCSS) roof materials in urban areas is of great significance for understanding the potential impact, challenges, and issues of these materials on urban sustainable development, human health, and the environment. Thanks to the development of Earth observation technologies, remote sensing (RS) provides abundant data to identify and map CCSS materials with different colors in urban areas. However, existing studies are still quite challenging with regards to the data collection and processing costs, particularly in wide geographical areas. Combining free access high-resolution RS data and a cloud computing platform, i.e., Sentinel-2A/B data sets and Google Earth Engine (GEE), this study aims at CCSS material identification and mapping. Specifically, six novel spectral indexes that use Sentinel-2A/B MSIL2A data are proposed for blue and red CCSS material identification, namely the normalized difference blue building index (NDBBI), the normalized difference red building index NDRBI, the enhanced blue building index (EBBI), the enhanced red building index (ERBI), the logical blue building index (LBBI) and the logical red building index (LRBI). These indexes are qualitatively and quantitatively evaluated on a very large number of urban sites all over the P.R. China and compared with the state-of-the-art redness and blueness indexes (RI and BI, respectively). The results demonstrate that the proposed indexes, specifically the LRBI and LBBI, are highly effective in visual evaluation, clearly detecting and discriminating blue and red CCSS covers from other urban materials. Results show that urban areas from the northern parts of P.R. China have larger proportions of blue and red CCSS materials, and areas of blue and red CCSS material buildings are positively correlated with population and urban size at the provincial level across China.
\end{abstract}

Keywords: logical blue building index (LBBI); logical red building index (LRBI); color-coated steel sheets (CCSS); urban building materials; sentinel-2; Google Earth Engine (GEE)

\section{Introduction}

Over the last few decades, the Earth's surface has experienced dramatic changes due, among other reasons, to rapid urbanization. This process is expected to continue for the rest of the 21st century, particularly for developing countries in Asia and Africa [1]. Today, more than $55 \%$ of the world population lives in towns and cities, which only occupy less than 
$0.60 \%$ of the global land surface, and by 2030 the number of the world urban population will swell to approximately 8.6 billion, more than $70 \%$ of the world population [2-5]. Along with this trend of global urbanization, the global urban area is expected to increase by roughly $40-67 \%$ until 2050 relative to the base year of 2013, with a growth ratio of more than $200 \%$ by the year $2100[1,6]$.

As one of the key elements in the process of development, urbanization has provided more and better living environments for more people worldwide and boosted economic developments, particularly for developing countries [7-11]. However, urbanization is also one of two major global environmental concerns of the 21st century [12,13], mainly because urban expansion has posed a wide range of challenges and issues to the socialeconomic, ecology, and environment at regional, national and global scales [1,6,14-21]. To mitigate potential risks and overcome issues caused by rapid urban expansion, it is of crucial importance to understand the pathways of urban growth. Thereby, numerous works have been documented with the subject of urban land cover or land use [22,23], urban extents [24,25], urban built-up areas [26-28], urban impervious surfaces [5,29,30], urban dynamics [20], urban nighttime lights [4,31-33], urban energy consumption [34,35], urban growth simulation and modeling [1,6,10,36,37], and so on.

Impacts, challenges, and issues following the trend of urban expansion are not only related to urban population density, urban area size and structure in both horizontal and vertical dimensions, environmental carrying capacity, geography and climatology background, water and land resources, planning and managing policy but they are also related to urban building types, patterns, and materials [38-46]. Hence, urban building extraction, building type identification, and pattern analysis are very important research topics with respect to both aspects of algorithmic and application studies in the field of urban remote sensing (URS) [47-52].

Specifically, building materials have significant impacts on urban energy consumption and flux by influencing electromagnetic (absorption, reflectivity, and emissivity) and electrochemistry properties of the built-up structures. They also influence building quality, safety, and serviceability, maintainability, and sustainability [44,53-60]. So far, in technical literature, only a few works have focused on building materials identification and building extraction with specific material using remote sensing (RS) imageries, and these works were carried out in small test areas [61-64]. This is mainly due to the fact that urban building materials have a great variety of types (e.g., woods, tiles, bricks, concrete, plastics, glass, metals, composites, and their combinations) with complex and diverse physicochemical properties and very complex geometrical shapes and structures.

Thanks to the development of Earth observation technologies, now urban building material types can be identified using hyperspectral, synthetic aperture radar (SAR), polarimetric SAR (PolSAR), light detection and ranging (LiDAR), and high or very highresolution (HR/VHR) multispectral instruments, capable of capturing information about physicochemical and geometrical properties [61,64-66]. However, challenging issues still remain open. For instance, spaceborne hyperspectral and LiDAR images have low and mid-spatial resolution and cannot capture detailed geometrical information about urban building materials. Spaceborne and airborne VHR visible and infrared images, as well as airborne LiDAR data, cannot provide sufficient spectral information about physicochemical properties of building materials [67-69]. SAR and PolSAR images, especially at high and very high spatial resolutions, suffer from speckle noise, and geometrical distortion effects become serious in areas with tall and dense buildings [70-72]. Because of these limitations, jointly using multispectral and hyperspectral images with HR and VHR spatial resolution, LiDAR data with HR and VHR spatial resolution, and multispectral images seem to be a possible solution. Still, these ideas are quite challenging to be implemented in wide geographical areas because of the heterogeneity between data sets and the data collection costs, hampering their usefulness in regional, national and global scale analysis scenarios. Hence, it is worth using more advanced but free accessible data sets on a cloud computing platform for urban building material identification in these scenarios. 
As an easily accessible and user-friendly cloud-based platform for planetary-scale geospatial data processing with massive computational capabilities, Google Earth Engine (GEE) has been in the big RS data processing and application spotlight in recent years $[73,74]$. The current GEE's open-source data catalog not only includes petabyte scales of over 40 years of RS data but also includes unprecedented volumes of geographic information system (GIS)-based vector data sets, climate, weather, social, demographic, geophysical, and ready-to-use products data layers [75]. Additionally, it provides a library of application programming interfaces (APIs) with a full-featured development environment for JavaScript and Python and an associated web-based interactive development environment (IDE) to interact with users. Owing to these advantages, GEE has led researchers to harness it for various applications, such as water, vegetation, ecosystem and biodiversity, natural hazards, agricultural, hydrology, urban, land cover, and many others [76-79].

Therefore, in this work, we focus on Sentinel-2A/B images with four bands at $10 \mathrm{~m}$ spatial resolution for specific material building identification and mapping over China using the GEE platform to detect color-coated steel sheets (CCSS). The contribution of urbanization to economic growth mainly comes from the construction industry and industrialization process that always have massive demands for construction materials. CCSS is composed of color-painted and galvanized steel plate surfaces with a polystyrene foam plastic sandwich layer [80]. In contrast with traditional roof materials such as wood, tiles, bricks, and concrete, CCSS has the properties of being lightweight, artistic, heat-insulation, soundproof, anti-corrosive, durable, stiff, easy to manufacture, and most importantly, it has a much lower market price. According to the CCSS industry and market search report of China for 2020, there were more than 13000 enterprises that produced more than 12 million tons of CCSS materials in 2019, and the value of the CCSS exchanging market was more than 70 billion RMB [81].

Nowadays, CCSS sheets are commonly found in urban areas, particularly on buildings for warehouses, stations, airport terminals, factories, logistic parks, supermarkets, stadiums, construction sites, vegetable greenhouses, farms, carports, dovecotes, as well as commercial and residential houses (Figure 1). Due to their easiness to manufacture and lower market price, CCSS sheets are mostly used for houses in shantytowns, as well as non-compliance and even illegal rooftop remodeling in downtown areas (Figure 1g). Despite the advanced properties mentioned earlier, CCSS materials may cause issues related to safety, serviceability, maintainability, and sustainability [58,82-84].

Additionally, from the eco-city planning and construction, urban and building color planning and design, urban ecological and environmental aesthetics, and bird-friendly urban color environment points of view, massively using CCSS materials in urban buildings is not the best option $[7,85-88]$. For instance, CCSS material can significantly impact local surface heat and urban energy consumption and flux by influencing electromagnetic absorption, reflectivity, and emissivity of the buildings. Thus, identifying and locating buildings covered with CCSS is an important task. To date, only a few works have focused on the CCSS material detection, mapping, and spatial pattern analysis in urban areas $[89,90]$.

Generally, CCSS materials can be painted in any color. However, since red mineral pigment is much cheaper than other ones, and blue color has better stability, and both red and blue CCSS materials have better thermal keeping capabilities than other colors. CCSS sheets with these two colors are much more commonly used in the construction industry. Thereby, most of the works of CCSS building identification and locating are focused on the red and blue CCSS material using supervised classification, object-oriented segmentation, and spectral matching methods $[65,66,83,89,90]$. It should be noted, however, that these somehow conventional approaches are labor intensive, inefficient, and impractical because of the material and urban landscape heterogeneity at large scales. Therefore, there is a great demand for methods that would allow for accurate and efficient up-to-date mapping of CCSS material buildings' spatial distribution in single urban areas, at regional and even national scales. 


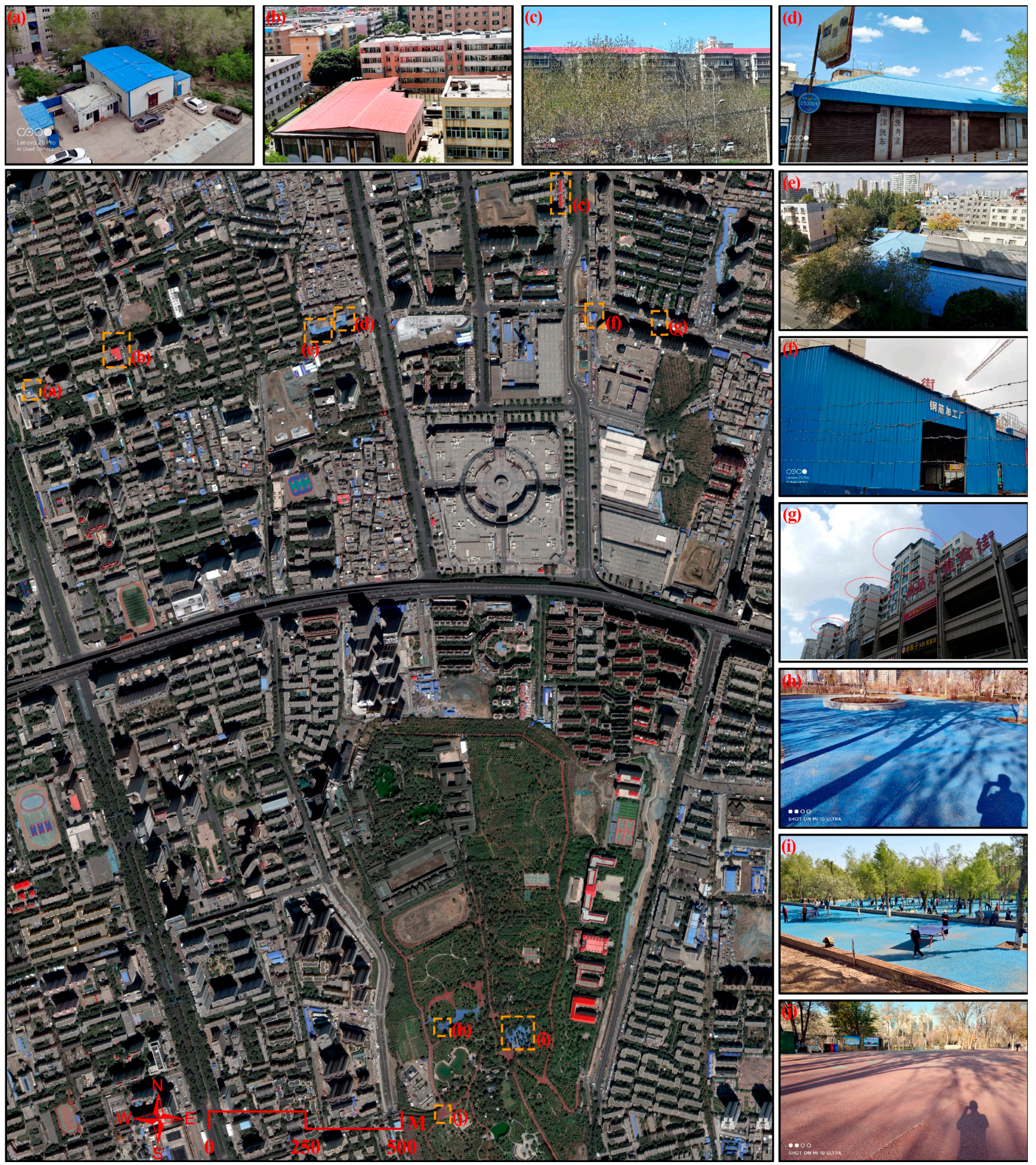

Figure 1. WorldView-3 RGB image captured on 22 July 2020 and ground photos of blue and red materials $(\mathbf{a}-\mathbf{j})$ around Liyushan Park at Urumqi City, Xinjiang, China.

In this study, Sentinel-2A/B MSIL2A images are used to develop several spectral indexes to enhance, identify and map blue and red CCSS sheets all over China, whose performance is comprehensively evaluated. Additionally, a detailed correlation between the CCSS sheet total area and the urban population is performed and discussed. 


\section{Study Area and Materials}

\subsection{Study Area}

The study area in this paper is the whole of P.R. China, which has experienced dramatic land changes due to an extremely rapid urbanization process in the past several decades, and it is currently the world's most populous country with an uneven process of development and urbanization across the country. Before mapping blue and red CCSS roof buildings, performances of the proposed method need to be proved by enough experiments using both qualitative and quantitative measures. To this aim, we selected 32 test sites all over the world representing a variety of locations, landscapes, city sizes, and urbanization levels to assess the proposed methods. As detailed in Figure 2 and Table 1, a total of 16 sites were selected from 11 provinces and counties across mainland China, 9 sites across Northeast, Central, Western, and Southeast Asia, and finally, 7 sites were selected across Eastern and Southern Africa.

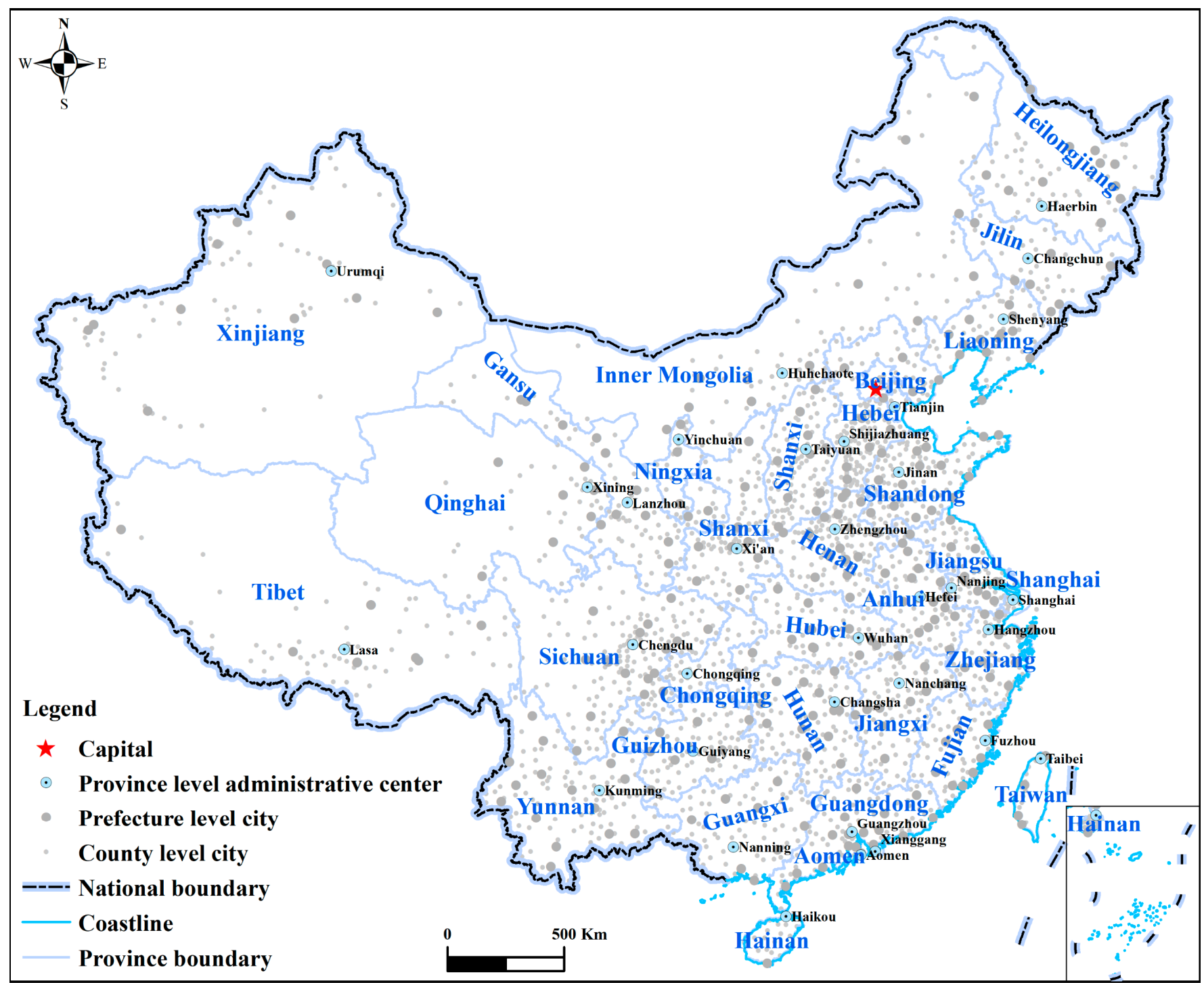

Figure 2. Study area and the distribution of the cities used as test sites over China. 
Table 1. Detailed information for the selected test sites.

\begin{tabular}{|c|c|c|c|c|c|c|c|}
\hline \multirow{2}{*}{ Site No. } & \multirow{2}{*}{ Country } & \multirow{2}{*}{ City Name } & \multicolumn{2}{|c|}{ Scene Center Location } & \multirow{2}{*}{$\begin{array}{c}\text { Spacecraft } \\
\text { Name }\end{array}$} & \multirow{2}{*}{$\begin{array}{l}\text { Orbit } \\
\text { Number }\end{array}$} & \multirow{2}{*}{ Sensing Time } \\
\hline & & & Latitude & Longitude & & & \\
\hline 1 & China & Urumqi & $43^{\circ} 43^{\prime} 24^{\prime \prime}$ & $87^{\circ} 35^{\prime} 20^{\prime \prime}$ & Sentinel-2A & 19 & 2020-10-15T08:04:29 \\
\hline 2 & China & Urumqi & $43^{\circ} 55^{\prime} 2^{\prime \prime}$ & $87^{\circ} 21^{\prime} 60^{\prime \prime}$ & Sentinel-2A & 19 & 2020-10-15Т08:04:29 \\
\hline 3 & China & Urumqi & $43^{\circ} 50^{\prime} 25^{\prime \prime}$ & $87^{\circ} 18^{\prime} 17^{\prime \prime}$ & Sentinel-2A & 19 & 2020-10-15Т08:04:29 \\
\hline 4 & China & Urumqi & $43^{\circ} 43^{\prime} 57^{\prime \prime}$ & $87^{\circ} 22^{\prime} 12^{\prime \prime}$ & Sentinel-2A & 19 & 2020-10-15T08:04:29 \\
\hline 5 & China & Chuzhou & $32^{\circ} 18^{\prime} 57^{\prime \prime}$ & $118^{\circ} 23^{\prime} 10^{\prime \prime}$ & Sentinel-2A & 132 & 2019-09-19T08:23:30 \\
\hline 6 & China & Haerbin & $45^{\circ} 37^{\prime} 12^{\prime \prime}$ & $126^{\circ} 37^{\prime} 14^{\prime \prime}$ & Sentinel-2A & 89 & 2020-10-20T05:26:23 \\
\hline 7 & China & Hefei & $31^{\circ} 41^{\prime} 49^{\prime \prime}$ & $117^{\circ} 11^{\prime} 33^{\prime \prime}$ & Sentinel-2A & 132 & 2020-10-23T05:38:54 \\
\hline 8 & China & Tianjin & $39^{\circ} 21^{\prime} 8^{\prime \prime}$ & $117^{\circ} 43^{\prime} 40^{\prime \prime}$ & Sentinel-2B & 32 & 2020-09-01T05:56:11 \\
\hline 9 & China & Tianjin & $39^{\circ} 16^{\prime} 49^{\prime \prime}$ & $117^{\circ} 49^{\prime} 24^{\prime \prime}$ & Sentinel-2B & 32 & 2020-09-01T05:56:11 \\
\hline 10 & China & Xining & $36^{\circ} 41^{\prime} 43^{\prime \prime}$ & $101^{\circ} 44^{\prime} 56^{\prime \prime}$ & Sentinel-2A & 4 & 2020-04-27T08:09:55 \\
\hline 11 & China & Changchun & $43^{\circ} 54^{\prime} 2^{\prime \prime}$ & $125^{\circ} 26^{\prime} 42^{\prime \prime}$ & Sentinel-2A & 89 & 2020-10-20T05:26:23 \\
\hline 12 & China & Yinchuan & $38^{\circ} 27^{\prime} 33^{\prime \prime}$ & $106^{\circ} 6^{\prime} 32^{\prime \prime}$ & Sentinel-2A & 104 & 2020-05-14T08:36:42 \\
\hline 13 & China & Shihezi & $44^{\circ} 25^{\prime} 56^{\prime \prime}$ & $86^{\circ} 5^{\prime} 14^{\prime \prime}$ & Sentinel-2B & 19 & 2020-07-22T09:30:27 \\
\hline 14 & China & Shenyang & $41^{\circ} 57^{\prime} 2^{\prime \prime}$ & $123^{\circ} 32^{\prime} 56^{\prime \prime}$ & Sentinel-2B & 89 & 2020-06-07T05:18:53 \\
\hline 15 & China & Shenyang & $41^{\circ} 45^{\prime} 46^{\prime \prime}$ & $123^{\circ} 14^{\prime} 23^{\prime \prime}$ & Sentinel-2B & 89 & 2020-06-07T05:18:53 \\
\hline 16 & China & Shijiazhuang & $38^{\circ} 4^{\prime} 29^{\prime \prime}$ & $114^{\circ} 2^{\prime} 10^{\prime \prime}$ & Sentinel-2A & 75 & 2020-09-19T06:06:33 \\
\hline 17 & Iran & Tehran & $35^{\circ} 27^{\prime} 41^{\prime \prime}$ & $51^{\circ} 21^{\prime} 46^{\prime \prime}$ & Sentinel-2B & 6 & 2020-09-19T09:56:38 \\
\hline 18 & Iran & $\begin{array}{l}\text { Caspian Industral } \\
\text { Twon }\end{array}$ & $36^{\circ} 11^{\prime} 9^{\prime \prime}$ & $50^{\circ} 16^{\prime} 47^{\prime \prime}$ & Sentinel-2A & 6 & 2020-10-24T09:47:55 \\
\hline 19 & Kazakhstan & Nursurtan & $51^{\circ} 10^{\prime} 17^{\prime \prime}$ & $71^{\circ} 31^{\prime} 6^{\prime \prime}$ & Sentinel-2A & 34 & 2020-10-16T08:53:32 \\
\hline 20 & South Korea & Pusan & $128^{\circ} 51^{\prime} 22^{\prime \prime}$ & $35^{\circ} 05^{\prime} 45^{\prime \prime}$ & Sentinel-2A & 103 & 2020-04-24T02:07:01 \\
\hline 21 & South Korea & Inchon & $126^{\circ} 37^{\prime} 23^{\prime \prime}$ & $37^{\circ} 32^{\prime} 52^{\prime \prime}$ & Sentinel-2A & 3 & 2020-10-24T04:59:15 \\
\hline 22 & Maynmaer & Yangon & $96^{\circ} 17^{\prime} 28^{\prime \prime}$ & $16^{\circ} 50^{\prime} 17^{\prime \prime}$ & Sentinel-2A & 4 & 2020-12-13Т04:01:51 \\
\hline 23 & Malaysia & Kuala Lumpur & $2^{\circ} 57^{\prime} 24^{\prime \prime}$ & $101^{\circ} 19^{\prime} 37^{\prime \prime}$ & Sentinel-2A & 18 & 2020-02-28T07:41:37 \\
\hline 24 & Cambodia & Phnom Penh & $11^{\circ} 27^{\prime} 53^{\prime \prime}$ & $104^{\circ} 54^{\prime} 15^{\prime \prime}$ & Sentinel-2A & 118 & 2019-12-07T07:19:12 \\
\hline 25 & Vietnam & Ho Chi Minh City & $106^{\circ} 28^{\prime} 43^{\prime \prime}$ & $10^{\circ} 46^{\prime} 44^{\prime \prime}$ & Sentinel-2A & 118 & 2020-01-21T03:20:39 \\
\hline 26 & South Africa & Pretoria & $-25^{\circ} 49^{\prime} 15^{\prime \prime}$ & $28^{\circ} 11^{\prime} 41^{\prime \prime}$ & Sentinel-2A & 135 & 2020-10-23Т10:15:14 \\
\hline 27 & Rwanda & Kigali & $-1^{\circ} 57^{\prime} 3.85^{\prime \prime}$ & $30^{\circ} 9^{\prime} 27.27^{\prime \prime}$ & Sentinel-2A & 78 & 2019-09-15T08:06:11 \\
\hline 28 & Lesotho & Maseru & $-29^{\circ} 19^{\prime} 48.12^{\prime \prime}$ & $27^{\circ} 28^{\prime} 3^{\prime \prime}$ & Sentinel-2A & 135 & 2020-09-13T10:23:18 \\
\hline 29 & Zimbabwe & Harare & $-17^{\circ} 50^{\prime} 12.58^{\prime \prime}$ & $27^{\circ} 28^{\prime} 2.74^{\prime \prime}$ & Sentinel-2A & 135 & 2020-10-28Т07:50:29 \\
\hline 30 & Kenya & Nairobi & $-1^{\circ} 20^{\prime} 7^{\prime \prime}$ & $36^{\circ} 53^{\prime} 12^{\prime \prime}$ & Sentinel-2B & 92 & 2020-10-05T10:20:29 \\
\hline 31 & Ethiopia & Addis Ababa & $8^{\circ} 46^{\prime} 1^{\prime \prime}$ & $38^{\circ} 55^{\prime} 42^{\prime \prime}$ & Sentinel-2B & 92 & 2020-01-19T10:14:10 \\
\hline 32 & Uganda & Kampala & $0^{\circ} 21^{\prime} 21^{\prime \prime}$ & $32^{\circ} 49^{\prime} 23^{\prime \prime}$ & Sentinel-2A & 35 & 2019-12-31T10:42:04 \\
\hline
\end{tabular}

\subsection{Materials}

Sentinel-2 mission is a constellation of twin polar-orbiting satellites (Sentinel-2A and Sentinel-2B) developed and operated by European Space Agency (ESA) [91]. Both Sentinel2A and Sentinel-2B carry the state-of-the-art multispectral instrument (MSI) sensor that offers spectral bands spanning from the visible (VIS) and the near infrared (NIR) to the short wave infrared (SWIR) at different spatial resolutions at the ground, ranging from 10 to $60 \mathrm{~m}$. By sharing the same sun-synchronous orbit at an altitude of $\sim 786 \mathrm{~km}$ but separated by $180^{\circ}$, Sentinel-2A/B can provide better than a 5-day revisit of the Earth's land surface with an equatorial overpass time at approximately 10:30 a.m. All the Sentinel-2 data used in this study are level-2A (L2A) bottom of atmosphere (BOA) corrected reflectance products, which means per-pixel radiometric measurements are provided in surface reflectance with all parameters to transform them into radiance. Only the visual bands of blue (band 2), green (band 3), red (band 4), and the near-infrared (band 8) with $10 \mathrm{~m}$ spatial resolution were used in this study. All images of the selected test sites in Table 1 were processed using the Sentinel Application Platform (SNAP, v8.0), which is a free, open-source software program that is distributed by the ESA-ESRIN (Frascati, Rom, Italy) under the GNU General Public License and funded through the ESA Scientific Exploration of Operational Missions (SEOM) Program.

The urban class from the global land cover with fine classification system at $30 \mathrm{~m}$ in 2020 product (GCL-FCS30-2020) [92]) and Global Human Settlements from Sentinel-2 satellite imagery using convolutional neural networks (GLS-S2Net-2018) product [93] were selected to discard the areas outside human settlements. 


\section{Methods}

\subsection{Spectral Analysis and Normalized Difference Indexes Development}

To extract and map blue and red CCSS material buildings in an accurate, fast and unsupervised manner, it is important to analyze and understand the spectral properties of the CCSS materials. To this aim, Figure 3 presents Sentinel-2A average image spectra of blue and red CCSS materials and other land cover types collected around carp fish mountain park at Urumqi City, Xinjiang, China.
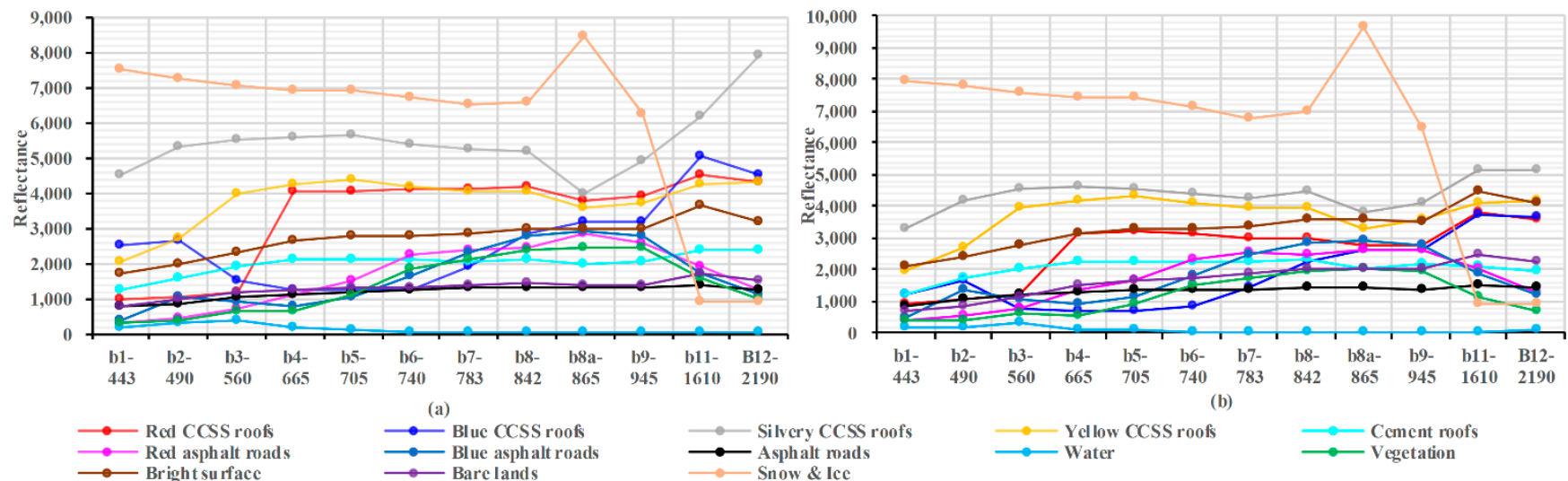

Figure 3. Sentinel 2-A MSIL2A average image spectra of CCSS materials and other land cover types collected from upper half (a) and lower half (b) parts of Figure 1.

According to the graphs in Figure 3, it can be observed that the spectral responses of different CCSS materials are highly variable with respect to both reflectance patterns and magnitudes. For instance, red CCSS material roofs have a nearly flat spectral curve between the wavelength of 443-560 $\mathrm{nm}$ and 665-945 $\mathrm{nm}$ and have two absorption valleys at the spectral range of red to green (560-565 nm) and water vapor to SWIR (945-1610 nm), which have the potential to distinguish them from other roof types. Compared with the first absorption value, the absorption valley at the spectral range of 945-1610 nm has smoother slopes and overlaps less with the absorption valleys of yellow CCSS roofs, silvery CCSS roofs, bright surfaces, and blue CCSS roofs. Additionally, considering that bands in the spectral range of 560-565 have a higher spatial resolution $(10 \mathrm{~m})$ than the bands in the spectral range of 945-1610 $(20 \mathrm{~m}, 60 \mathrm{~m})$, the absorption valley at 560-565 nm has better potential to detect red CCSS materials. Hence, following the simplicity of normalized difference indexes such as the normalized difference vegetation index (NDVI) and the normalized difference water index (NDWI) [94,95], an option would be to define a normalized difference red building index (NDRBI) as follow:

$$
\mathrm{NDRBI}=\frac{\beta_{4}-\beta_{3}}{\beta_{4}+\beta_{3}}
$$

where $\beta_{3}$ and $\beta_{4}$ represent the third (green) and fourth (red) Sentinel 2-A/B spectral bands.

Looking now at the spectral reflectance shown by the square marked blue line, the blue CCSS material has a nearly flat spectral curve between in the wavelength of 560-740 nm and two absorption valleys in the spectral ranges of 490-560 nm and 945-1160 nm, which also may have potential to distinguish blue CCSS material from others. However, the latter absorption valley almost overlaps with the absorption valleys of other bright surfaces, such as silvery red CCSS roofs. In comparison with the spectra of other land cover types, only the slope of the former absorption valley at the spectral range of 490-560 nm shown by blue CCSS material roofs is in an anti-direction. Therefore, the normalized difference blue building index (NDBBI) may be defined as: 


$$
\mathrm{NDBBI}=\frac{\beta_{2}-\beta_{3}}{\beta_{2}+\beta_{3}}
$$

where $\beta_{2}$ and $\beta_{3}$ represent the second (blue) and third (green) Sentinel 2-A/B spectral bands.

\subsection{Enhanced Blue and Red Building Indexes}

Although useful, the normalized indexes proposed above may not be able to provide results that are suitable enough. Indeed, absorption valleys in the 560-665 $\mathrm{nm}$ range exist for yellow CCSS materials, bright surfaces, red asphalt roads, and bare lands, and in the 490-560 nm range for snow, ice, and blue asphalt roads. Therefore, NDRBI may also enhance yellow CCSS roofs, bright surfaces, red asphalt roads, and bare lands land cover types in addition to red CCSS roofs, while NDBBI may also enhance snow and ice and blue asphalt roads other than blue CCSS roofs. To partially solve this issue, considering that blue CCSS roof reflectance at $490 \mathrm{~nm}$ (blue) is always higher (at least two times) than the reflectance at $560 \mathrm{~nm}$ (green) and $665 \mathrm{~nm}$ (red), while snow and ice, bare lands and asphalt roads have a flat spectral response in the same range, an enhanced blue building index (EBBI) can be proposed as follows:

$$
\mathrm{EBBI}=\frac{2 \beta_{2}-\left(\beta_{3}+\beta_{4}\right)}{2 \beta_{2}+\left(\beta_{3}+\beta_{4}\right)}
$$

Similarly, considering that red CCSS roof reflectance at $665 \mathrm{~nm}$ (red) is always higher (at least three times) than the reflectance at $490 \mathrm{~nm}$ (blue) and $560 \mathrm{~nm}$ (green), it has similar and even higher reflectance at $842 \mathrm{~nm}$ (NIR), while silvery CCSS roofs, cement roofs, and asphalt roads have flat spectral responses at 560 and $842 \mathrm{~nm}$, an enhanced red building index (ERBI) can be proposed as follows:

$$
\mathrm{ERBI}=\frac{3 \beta_{4}-\left(\beta_{2}+\beta_{3}+\beta_{8}\right)}{3 \beta_{4}+\left(\beta_{2}+\beta_{3}+\beta_{8}\right)}
$$

where, in addition to the bands mentioned in the previous formulas, $\beta_{8}$ represents the eighth (NIR) Sentinel 2-A/B spectral band.

\subsection{Logical Blue and Red Building Indexes}

The two previously presented sets of indexes assume already values in a limited range but need to be thresholded to eventually detect red or blue CCSS roofs. The selection of a threshold is always a complex task, especially when considering a very large geographical area. Therefore, a third set of indexes is proposed here, which are already and inherently binary values. To this aim, looking again at the reflectance spectra shown in Figure 3, it can be noted that only the blue CCSS material has a U-shape spectral reflectance pattern considering Sentinel 2 bands n. 2 (blue), 3 (green), 4 (red) and 8 (NIR) and that the reflectance values for bands n. 2 and 8 are always larger than the values for bands 3 and 4 . Based on this reflectance pattern, a logical blue building index (LBBI) can be defined as follows:

$$
\mathrm{LBBI}=\left\{\begin{array}{c}
1, \text { if } \beta_{2}>\beta_{3} \text { and } \beta_{2}>\beta_{4} \text { and } \beta_{8}>\beta_{3} \text { and } \beta_{8}>\beta_{4} \\
0
\end{array}\right.
$$

Considering instead the spectral reflectance pattern for the red CCSS material, it may be considered as a ladder-shaped spectral reflectance pattern considering again Sentinel 2 bands No. 2, 3, 4, and 8, and that the reflectance values for bands NO. 2 and 3 are always smaller than the values for bands n. 4 and 8. Unfortunately, this kind of spectral feature can be observed for other land cover types, too, such as yellow CCSS roofs, bright surfaces, bare land, and cement roofs. However, the reflectance values of red CCSS roofs for bands NO. 4 and 8 (>3000) are at least three times larger than the corresponding values for bands NO. 2 and 3 ( $\geq 1000)$, while for yellow CCSS roofs, bright surfaces, bare land, and cement 
roofs, the same ration is between one and one point five times. Accordingly, even for red CCSS roofs, a novel logical red building index (LRBI) can be defined as follows:

$$
\mathrm{LRBI}=\left\{\begin{array}{c}
1, \text { if } \beta_{4}>2 * \beta_{2} \text { and } \beta_{4}>2 * \beta_{3} \text { and } \beta_{8}>2 * \beta_{2} \text { and } \beta_{8}>2 * \beta_{3} \\
0
\end{array}\right.
$$

\subsection{Blue and Red Building Extraction Method}

In the previous Section 3.1, Section 3.2, and Section 3.3, several indexes for blue and red CCSS material extraction have been proposed. To avoid as much as possible limitations due to cloud coverage, only Sentinel 2-A/B MSIL2A images with less than 10\% cloud coverage were collected from Copernicus Open Access Hub. Moreover, as mentioned above, to reduce false positives, the GHS-S2Net-2018 map and the urban class from GLC-FCS30-2020 were fused to mask out anything outside the urban areas. The technical steps for blue and red building extraction are presented in Figure 4:

Step 1: Collect Sentinel-2 A/B S2MSIL2A images with cloud cover ratio lower than 10\% that coverage for the whole of China from Copernicus Open Access Hub for 2020;

Step 2: Obtain the preliminary maps for blue and red CCSS buildings by applying Equations (5) and (6) on the median images of S2MSIL2A image collections;

Step 3: Produce the urban area map for 2020 by fusion of GHS-S2Net-2018 and GLC-FC302020 products;

Step 4: Obtain the refined maps for blue and red CCSS buildings by masking the preliminary maps produced by step 2 with the urban area map produced by step 3;

Step 5: Evaluate the performance of the proposed methods on the city sites that selected over different countries with various landscapes;

Step 6: Analysis for distributions and patterns of blue and red CCSS buildings for China in 2020.

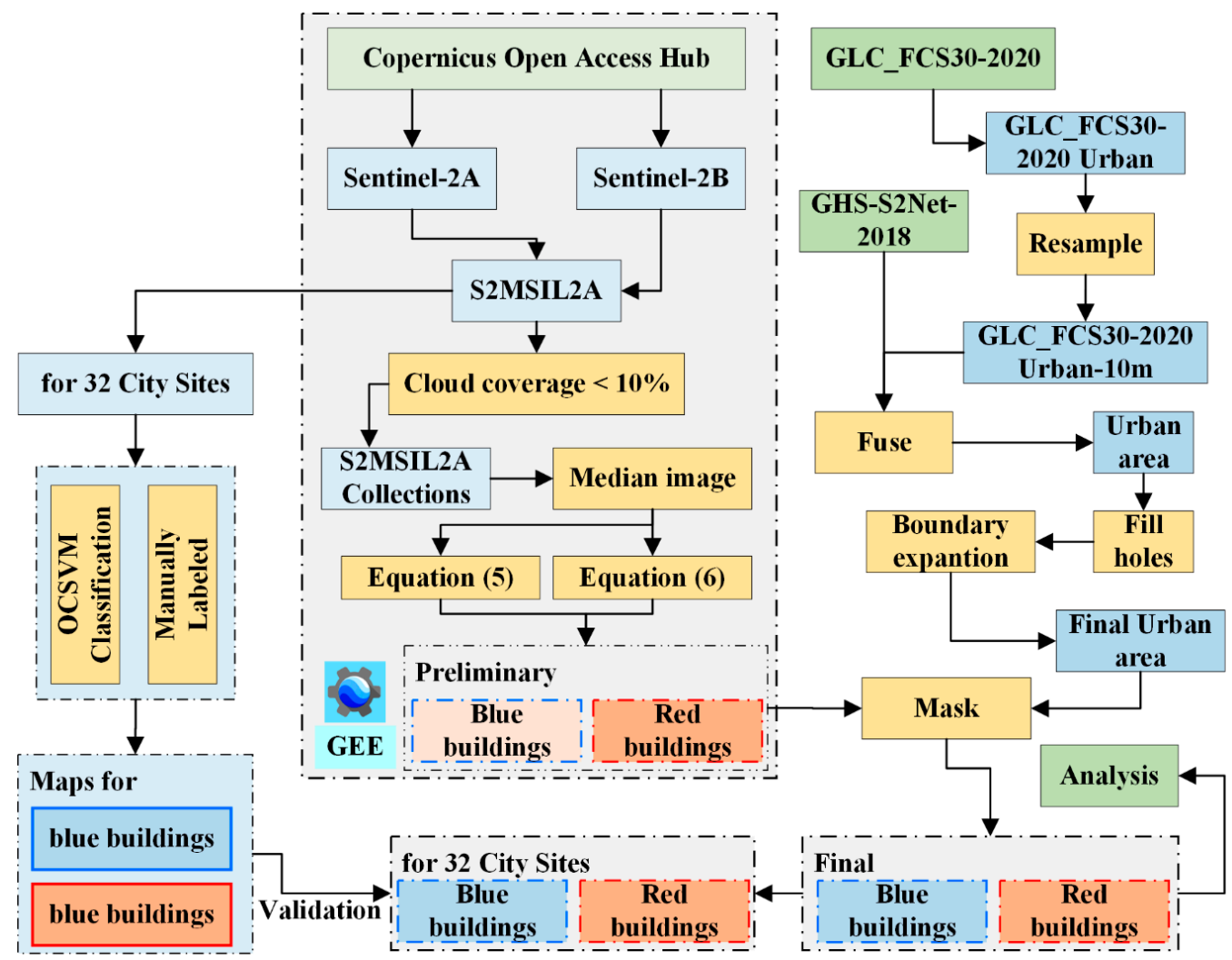

Figure 4. Technical steps for blue and red CCSS buildings extraction. 


\subsection{Experimental Setups}

To comparatively evaluate and show the performance of the proposed indexes (NDBBI, NDRBI, EBBI, and ERBI), two established indexes, the redness index (RI) and the blueness index (BI), originally developed for soil identification and classification based on soil color Landsat TM data [96], were employed. RI and BI are defined as:

$$
\begin{aligned}
& \mathrm{RI}=\frac{\beta_{4}}{\beta_{2}+\beta_{3}+\beta_{4}} \\
& \mathrm{BI}=\frac{\beta_{2}}{\beta_{2}+\beta_{3}+\beta_{4}}
\end{aligned}
$$

where $\beta_{2}, \beta_{3}$, and $\beta_{4}$ represent the second (blue), third (green), and fourth (red) Sentinel 2-A/B spectral bands.

Additionally, a one-class support vector machine (OCSVM) classifier, with radial basis function (RBF) kernel from the library for SVM (LIBSVM) toolbox provided by Chang, C.C. and Lin [97] was also used to extract maps to be compared with those by the proposed indexes. For the free parameters of OCSVM, a grid $(10 \times 10)$ searching criterion and 3-fold cross-validation technique was adopted by setting the searching range for $\lambda$ to $(0.01-10)$ and the cost factor range to (1-1000). As evaluation metrics, overall accuracy (OA), Kappa statistic, omission error $(\mathrm{OE})$, and commission error $(\mathrm{CE})$ were selected. All reference maps used in the following experiments were collected by photo-interpretation of RGB ( $\mathrm{R}=$ band $4, \mathrm{G}=$ band 3, $\mathrm{B}=$ band 2 ) composites of Sentinel 2-A/B images and further referring to the high-resolution optical images in Google Earth.

\section{Results and Discussion}

\subsection{Visual Evaluation of NDBSI, NDRSI, EBBI, and ERBI Indexes}

To show the performance of NDBBI, NDRBI, EBBI, and ERBI indexes for blue and red CCSS roof enhancement, nine distinct sites with different landscape heterogeneity were selected from the Sentinel 2-A image captured on 15 October 2020 over Urumqi. Figure 5 shows the NDBBI, NDRBI, EBBI, and ERBI images for these test sites.

By visually comparing with RGB reference images in the first column and RI and BI images in the sixth and seventh column of Figure 5, most of the blue and red CCSS roof buildings are highlighted by the proposed NDBBI, NDRBI, EBBI, and ERBI. More in detail, while blue CCSS roofs, blue painted asphalt roads as shown by Figure $1 \mathrm{~b}$ and highlighted with a green rectangle at the bottom of images in the fifth row, construction sites covered by blue nets highlighted with a green rectangle at the right edge of images in the seventh row, snow coverage and hill shadows as shown by the RGB image in the eighth row, are similarly highlighted by NDBBI due to the spectral similarity, and even some water (the Yanerwo lake) is highlighted by BI as shown by the sixth image in firth row, the contrast between blue CCSS roofs and the backgrounds is much higher in the EBBI images in column four. Unfortunately, due to the high and almost flat spectral reflectance at visible spectral bands, some silvery roof buildings and snow patches such as the oil storage tanks highlighted by a pink rectangle in the right images of the third row, the Olympic Center building highlighted by a pink rectangle in the upper-left corner of the images of the fifth row, and the high-speed rail station highlighted by s pink rectangle at the bottom of the images of the seventh row, are also highlighted by EBBI.

In contrast with the results shown by NDRBI and RI images in the third and seventh columns, the improvements by ERBI shown by the images in the fifth column of Figure 5 are clear. For example, NDRBI and IR both enhance red-painted asphalt roads in Yanerwo Park and Liyushan Park, marked by pink rectangles at the bottom center of the images in the first and fifth rows, as well as the plastic racetracks marked by pink rectangles at the middle right of the images in the fourth row, at the upper left of the images in the fifth row, and at the bottom right of the images in the eighth row. They also wrongly enhance rust-colored hill surfaces between two lakes, marked by a pink rectangle at the left edge 
of the images in the sixth row. Instead, ERBI enhances only the red CCSS roofs, but it has some limitations in distinguishing silver and yellow CCSS roofs, such as in the areas marked by a pink rectangle at the right edge of the images in the third row and by a green rectangle in the upper-left edge of the images in the eighth row of Figure 5.

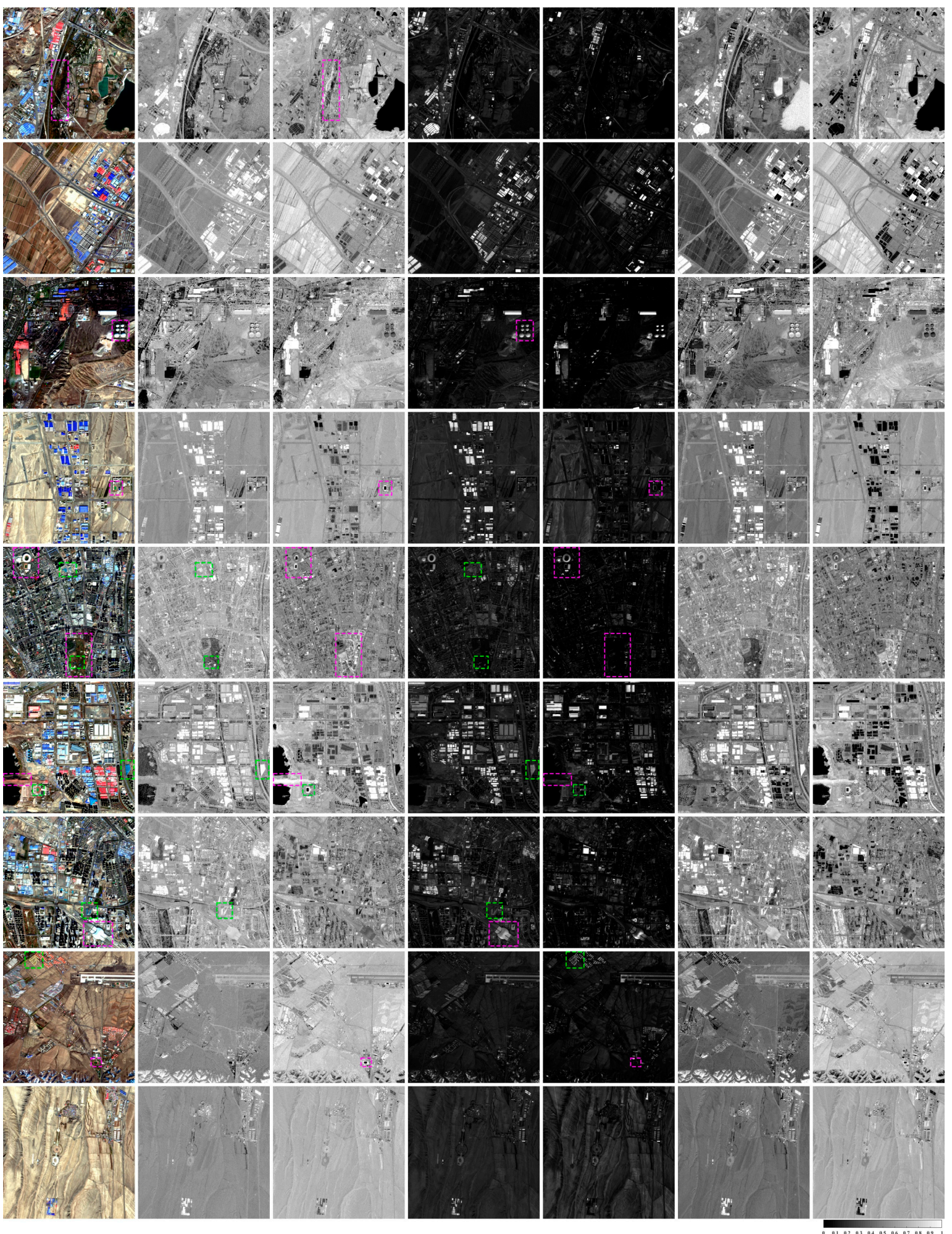

Figure 5. RGB images (column 1), NDBBI (column 2), NDRBI (column 3), EBBI (column 4), ERBI (column 5), BI (column 6) and RI (column 7) for total 9 test sites from Urumqi City. (Red numbers at the lower-left corner of RGB images represent the row number). 


\subsection{Results of $L B B I$ and $L R B I$}

To visually and quantitatively compare the performance of NDBBI, NDRBI, EBBI, ERBI, LBBI, and LRBI indexes for blue and red CCSS material roof buildings extraction, five distinct sites with different landscape heterogeneity were selected within the city of Urumqi. The mean-standard deviation plane method [98] was selected to produce binary results from NDBBI, NDRBI, EBBI, and ERBI indexes. Figure 6 shows the detected results for the considered test sites, while Table 2 presents the evaluation metrics.

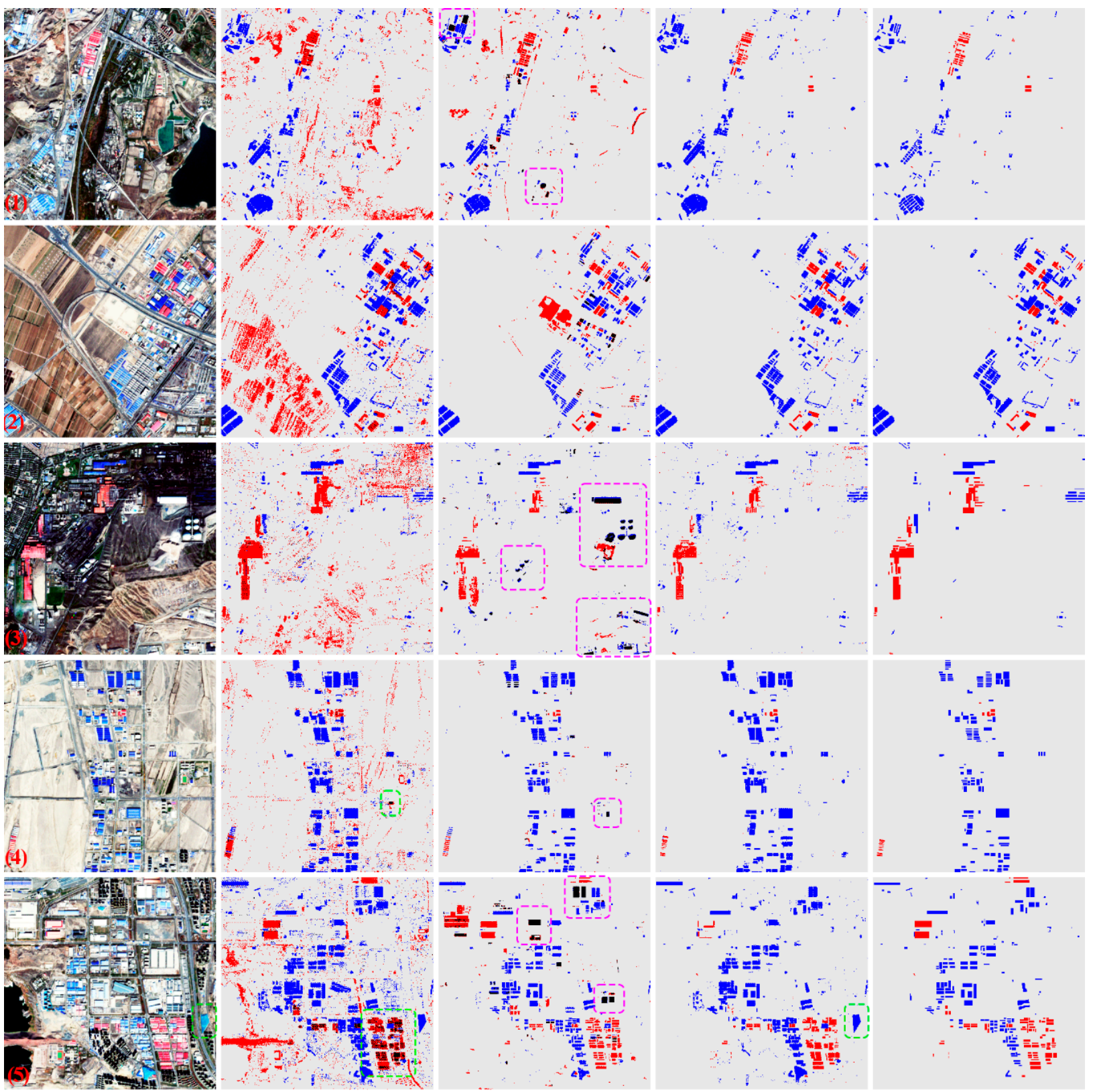

Figure 6. RGB images (column 1), mean-standard deviation plane method results using NDBBINDRBI (column 2), EBBI-ERBI (column 3), LBBI-LRBI (column 4), to be compared with the ground truth (column 5) for 5 test sites in the city of Urumqi (row numbers are included in red at the lower-left corner of the RGB images for an easier reference in the text).

Based on these results, it is notable that blue and red CCSS roofs can be detected by means of the mean-standard deviation plane method-based segmentation applied to NDBBI and NDRBI, but with a very high false-positive detection rate, particularly from the brown and rust-colored surfaces. For instance, the detection accuracy for NDBBI stays in 
the range of $92.88-98.57 \%$ with an average of $96.99 \%$ for $\mathrm{OA}$, in the range of $21.38-66.23 \%$ with an average of $48.49 \%$ for CE, while the detection accuracy for NDRBI stays in the range of $92.01-96.99 \%$ with an average of $94.34 \%$ for OA and in the range of $50.42-90.62 \%$ with an average of $75.79 \%$ for CE, as shown by the numbers in Table 2 . The results suing EBBI and ERBI are instead more accurate, but the best results are those by LBBI and LRBI, both visually and quantitatively. For instance, while brown and rust-colored hill surfaces in the first, second, third, and fifth test sites are successfully discarded by the analysis using ERBI, bright buildings such as oil storage tanks and silvery material roof buildings are still detected, as shown by the buildings marked with pink rectangles in the third column of Figure 6. On the contrary, only the blue nest-covered surfaces were detected as blue CCSS material by LBBI index, as marked by the green rectangle in the fourth image of the fifth row in the same figure.

Figures 7 and 8 present blue and red CCSS roof building detection results using LBBI, LRBI, and OCSVM for the sites listed in Table 1, while Table 3 shows the detection accuracy metrics, i.e., OA, Kappa, OE, and CE values.

By visually comparing the results shown in Figure 7 for the 16 sites in China and in Figure 8 for another 16 sites in other countries, and looking at the accuracy evaluation values in Table 2, it can be concluded that LBBI and LRBI are highly effective for blue and red CCSS roof building detection. For instance, the detection accuracy for LBBI stays in the range of $97.22-99.88 \%$ with an average of $98.98 \%$ for $\mathrm{OA}$, in the range of $0.08-22.26 \%$ with an average of $5.93 \%$ for $\mathrm{CE}$, in the range of $6.30-45.32 \%$ with an average of $21.52 \%$ for OE. LRBI, instead, reaches detection accuracy with OA values larger than $98.91 \%$ with an average of $99.79 \%$, CE values in the range of $1.43-34.10 \%$ with an average of $13.01 \%$, OE values in the range of $0.10-37.90 \%$ with an average of $10.82 \%$ for the 32 selected test sites. The high effectiveness of the proposed LBBI and LRBI can be further checked by comparing the average and standard deviation values with the accuracy assessment values by OCSVM for blue (OCSVM-BB) and red (OCSVM-RB) CCSS roof extraction, shown in the last two rows of Table 3. Considering the detection accuracy values for blue CCSS roofs as an example, both the average $(\mathrm{CE}=12.00 \%, \mathrm{OE}=23.13 \%)$ and standard deviation $(\mathrm{CE}=5.27 \%, \mathrm{OE}=15.93 \%)$ values for $\mathrm{CE}$ and $\mathrm{OE}$ by OCSVM-BB are larger than the average $(\mathrm{CE}=5.93 \%, \mathrm{OE}=21.52 \%)$ and standard deviation $(\mathrm{CE}=4.43 \%, \mathrm{OE}=11.69 \%)$ values for the same quantities using LBBI. Additionally, in comparison with NDBBI, NDRBI, EBBI, and ERBI, LBBI and LRBI are more effective in discriminating blue and red CCSS roofs from silvery CCSS ones, very bright buildings, as well as rust-colored surfaces. For instance, both blue and red CCSS roofs are clearly distinguished from oil storage tanks, rust-colored surfaces, and very bright buildings by LBBI and LRBI for test site (3) in Figure 7 in comparison with the images in the third row of Figure 5, for test site (9) in Figure 7 and for sites (26) and (27) in Figure 8 with respect to the images in the sixth row of Figure 5, and finally for test site (9) in Figure 7 and test site (25) in Figure 8 with respect to the fifth and sixth rows of Figure 5.

It is important to note at this point that, despite they are simple and intuitive, and they have a physical meaning, spectral indexes extracted from satellite data have performances that depend on the sensing conditions, and specifically by the status of the atmosphere, the type of landscape, and the season of acquisition. Still, we expect that LBBI and LRBI indexes are robust enough to cope with these issues. To this aim, detection results for several test sites using Sentinel 2-A and Sentinel 2-B MSIL2A images in different seasons and these indexes are shown in Figure 9. These results show that the worst detection results are always shown by images in the winter season where the land surface is covered by snow (see the images in the first column for sites (1) and (4)) or the vegetated mountain areas, presumably covered by fog (see the first column for site 20). Moreover, the LRBI index for red CCSS roof detection is apparently more robust than the LBBI index for blue CCSS roof detection in different landscapes because, as expected, false positives due to snow and fog mostly appear in the blue CCSS detection results. 
Table 2. Detection accuracy metrics for mean-standard deviation plane method results using NDBBI, NDRBI, EBBI and ERIB, LBBI, and LRBI for 5 sites correspond to Figure 6.

\begin{tabular}{|c|c|c|c|c|c|c|c|c|c|c|c|c|c|c|c|c|c|c|c|c|c|c|c|c|}
\hline \multirow{2}{*}{$\begin{array}{l}\text { Indexes } \\
\text { Evaluation } \\
\text { Metrics }\end{array}$} & \multicolumn{4}{|c|}{ NDBBI } & \multicolumn{4}{|c|}{ NDRBI } & \multicolumn{4}{|c|}{ EBBI } & \multicolumn{4}{|c|}{ ERBI } & \multicolumn{4}{|c|}{ LBBI } & \multicolumn{4}{|c|}{ LRBI } \\
\hline & $\begin{array}{l}\text { OA } \\
(\%)\end{array}$ & Kappa & $\begin{array}{l}\text { CE } \\
(\%)\end{array}$ & $\begin{array}{l}\mathrm{OE} \\
(\%)\end{array}$ & $\begin{array}{l}\text { OA } \\
(\%)\end{array}$ & Kappa & $\begin{array}{l}\mathrm{CE} \\
(\%)\end{array}$ & $\begin{array}{l}\mathrm{OE} \\
(\%)\end{array}$ & $\begin{array}{l}\text { OA } \\
(\%)\end{array}$ & Kappa & $\begin{array}{l}\text { CE } \\
(\%)\end{array}$ & $\begin{array}{l}\mathrm{OE} \\
\mathbf{( \% )}\end{array}$ & $\begin{array}{l}\text { OA } \\
(\%)\end{array}$ & Kappa & $\begin{array}{l}\text { CE } \\
(\%)\end{array}$ & $\begin{array}{l}\mathrm{OE} \\
(\%)\end{array}$ & $\begin{array}{l}\text { OA } \\
(\%)\end{array}$ & Kappa & $\begin{array}{l}\text { CE } \\
(\%)\end{array}$ & $\begin{array}{l}\mathrm{OE} \\
(\%)\end{array}$ & $\begin{array}{l}\text { OA } \\
(\%)\end{array}$ & Kappa & $\begin{array}{l}\text { CE } \\
(\%)\end{array}$ & $\begin{array}{l}\mathrm{OE} \\
(\%)\end{array}$ \\
\hline 1 & 98.01 & 0.68 & 45.70 & 4.10 & 94.88 & 0.16 & 90.62 & 0.47 & 98.22 & 0.69 & 42.14 & 10.48 & 97.64 & 0.29 & 82.54 & 7.98 & 98.35 & 0.72 & 4.53 & 40.84 & 99.80 & 0.82 & 14.45 & 20.60 \\
\hline 2 & 98.52 & 0.87 & 21.38 & 1.14 & 92.01 & 0.22 & 86.39 & 0.00 & 97.82 & 0.7 & 15.45 & 28.33 & 97.6 & 0. & 67.78 & 17.73 & 99.57 & 0. & 1.06 & 6.30 & 99.92 & 0.9 & 3.50 & 3.00 \\
\hline 3 & 98.57 & 0.56 & 58.71 & 11.91 & 93.89 & 0.3 & 76.28 & 0.07 & 97.31 & 0.3 & 79.04 & 43.03 & 97.1 & 0. & 63.99 & 35.16 & 99.19 & & 11.25 & 42.94 & 99.25 & 0. & 20.69 & 18.96 \\
\hline 4 & 96.99 & 0.65 & 50.42 & 0.04 & 96.99 & 0.65 & 50.42 & 0.04 & 98.71 & 0.81 & 29.43 & 3.29 & 99.62 & 0. & 71.61 & 35.18 & 98.12 & 0.7 & 0.08 & 38.86 & 99.94 & 0.8 & 14.98 & 17.14 \\
\hline 5 & 92.88 & 0.48 & 66.23 & 0.67 & 93.95 & 0.38 & 75.26 & 0.38 & 97.38 & 0.70 & 40.55 & 11.45 & 97.23 & 0.54 & 59.34 & 15.42 & 97.21 & 0.7 & 43.23 & 2.04 & 98.93 & 0. & 23.64 & 32.88 \\
\hline Average & 96.99 & 0.65 & 48.49 & 3.57 & 94.34 & 0.35 & 75.79 & 0.19 & 97.89 & 0.65 & 41.32 & 19.32 & 97.85 & 0.42 & 69.05 & 22.29 & 98.49 & 0.77 & 12.03 & 26.20 & 99.57 & 0.83 & 15.45 & 18.52 \\
\hline $\begin{array}{l}\text { Standard } \\
\text { deviation }\end{array}$ & 2.39 & 0.15 & 17.07 & 4.91 & 1.81 & 0.19 & 15.62 & 0.22 & 0.59 & 0.20 & 23.64 & 16.13 & 1.02 & 0.09 & 8.80 & 12.29 & 0.93 & 0.11 & 17.98 & 20.21 & 0.45 & 0.09 & 7.72 & 10.65 \\
\hline
\end{tabular}


Table 3. Detection accuracy metrics for LBBI, LRBI, and OCSVM on considered test sites.

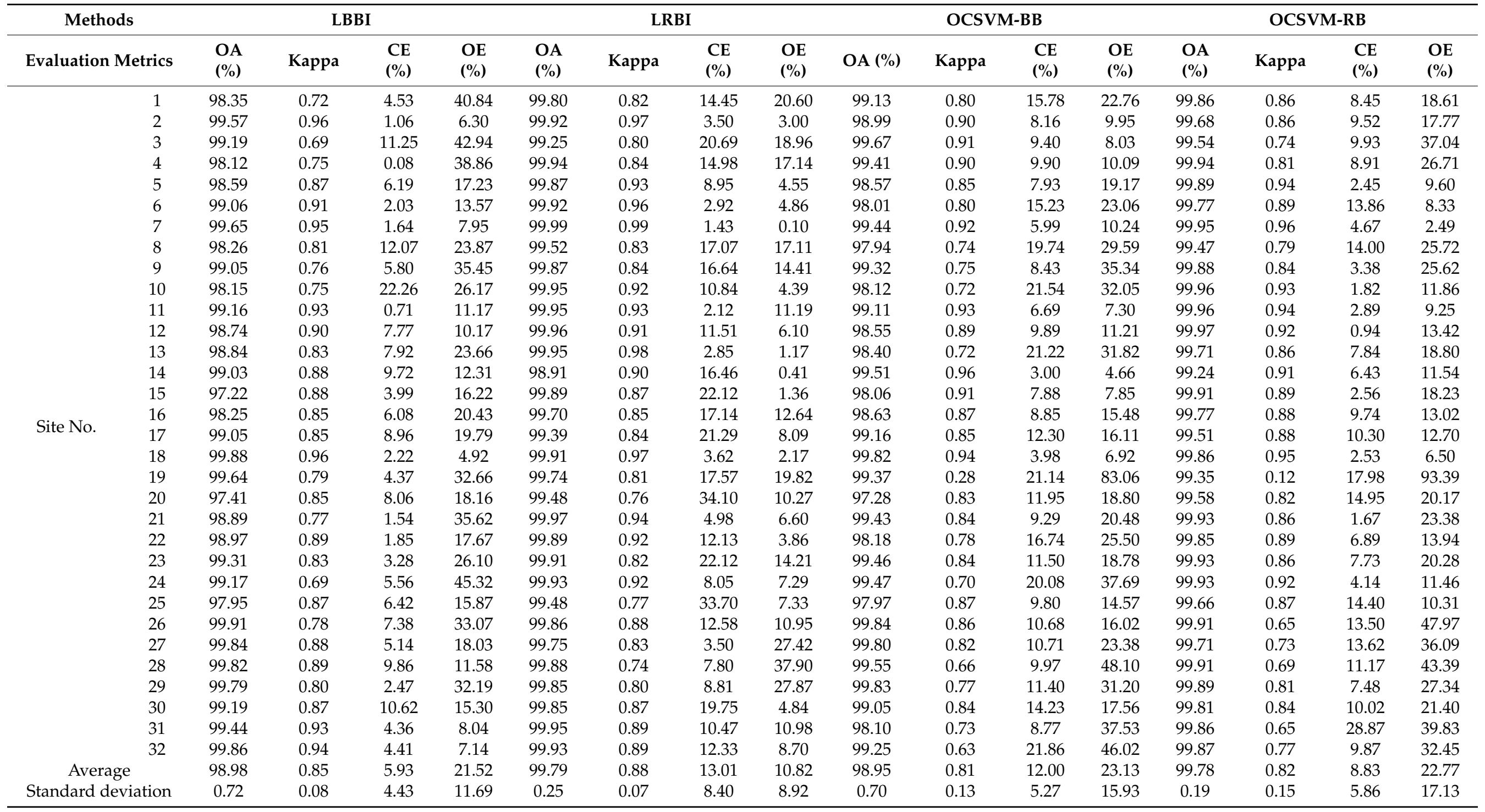


According to these results, only Sentinel 2-A/B MSIL2A images collected between April and October are used in the following extraction and the subsequent analyses.

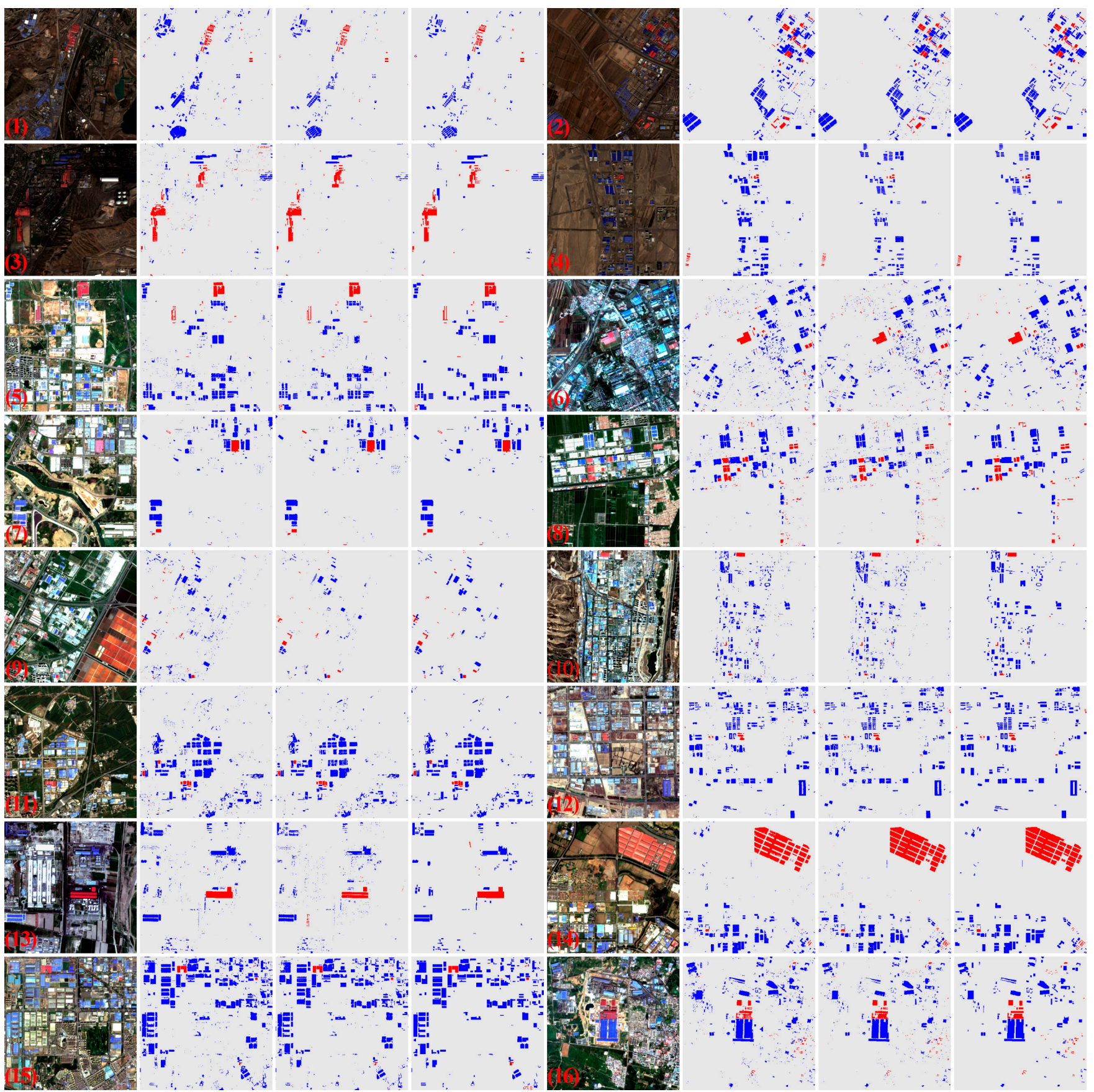

Figure 7. RGB images (columns 1, 5), detected results from LBBI and LRBI (column 2, 6), OCSVM (column 3, 7), and ground truths (column 4, 8) for 16 test sites from China (red numbers at the lower-left corner correspond to site numbers in Table 1, blue and red colors represent the detected blue and red buildings, respectively).

\subsection{Distributions and Patterns of Blue and Red CCSS Buildings for China}

Exploiting the technique described in Figure 4 and using the logical indexes, blue and red CCSS roofs were extracted for the urban areas across the whole of China. Figure 10 presents bar charts with dashed lines for the area in square meters $\left(\mathrm{m}^{2}\right)$ and the percentage of blue and red CCSS roof buildings with respect to urban extents at the provincial level in 2020. As mentioned, a large amount of CCSS materials can be usually found on buildings 
for warehouses, stations, airport terminals, factories, supermarkets, logistic parks, stadiums, and construction sites. Their distribution might thus be connected to socio-economic factors such as population, urbanization, and region development. Hence, in Figure 11, we present maps, colored with five levels, showing the total area of blue and red CCSS roofs and their relation to population (number of inhabitants), urban size $\left(\mathrm{m}^{2}\right)$, and GDP (RMB) at the provincial level in the same year.

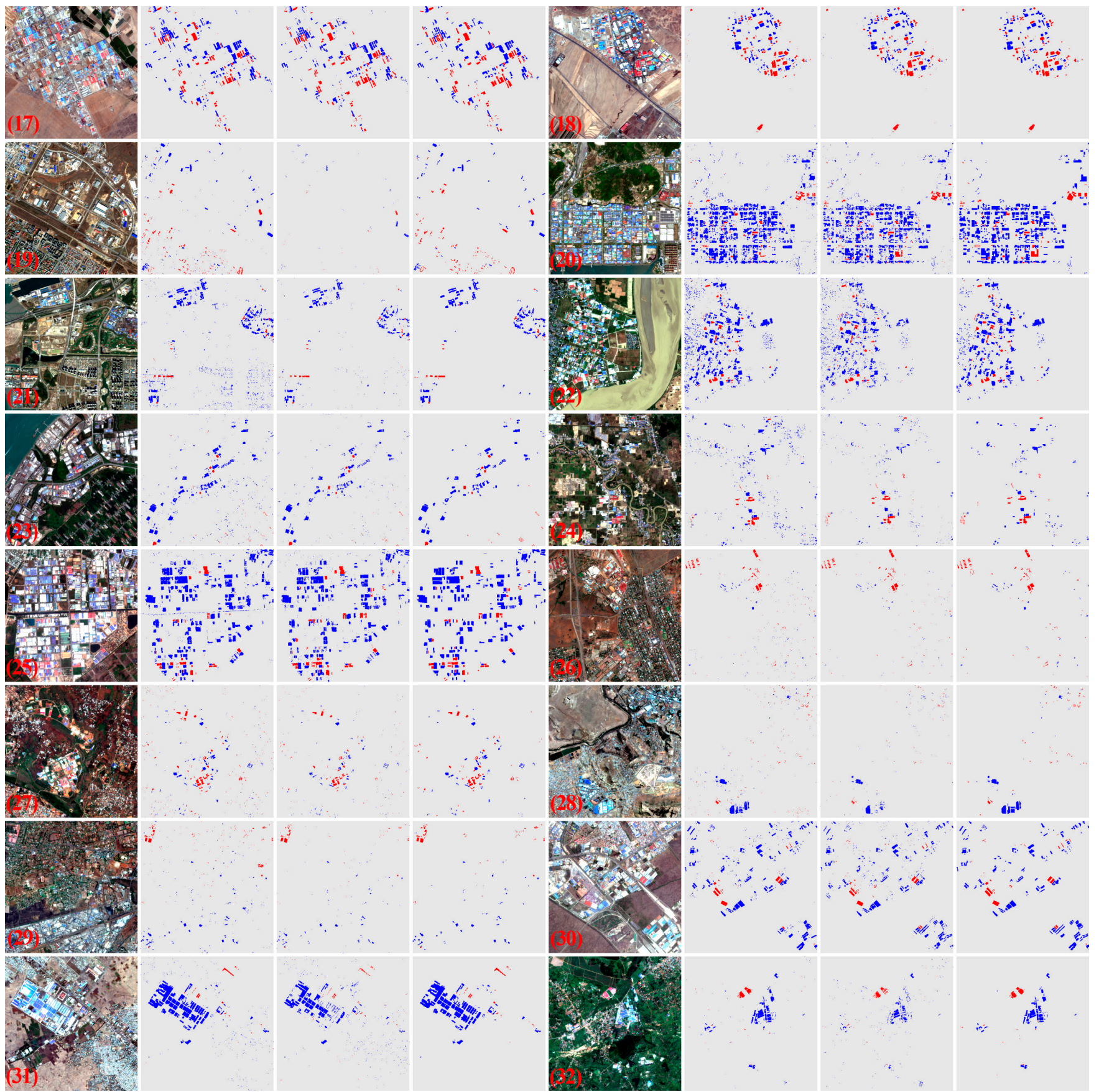

Figure 8. RGB images (columns 1, 5), detected results using LBBI and LRBI (columns 2, 6), OCSVM (columns 3, 7), and ground truths (columns 4, 8) for 16 test sites from Asia and Africa (red numbers at the lower-left corner correspond to the site number in Table 1, blue and red colors represent the detected blue and red buildings, respectively). 

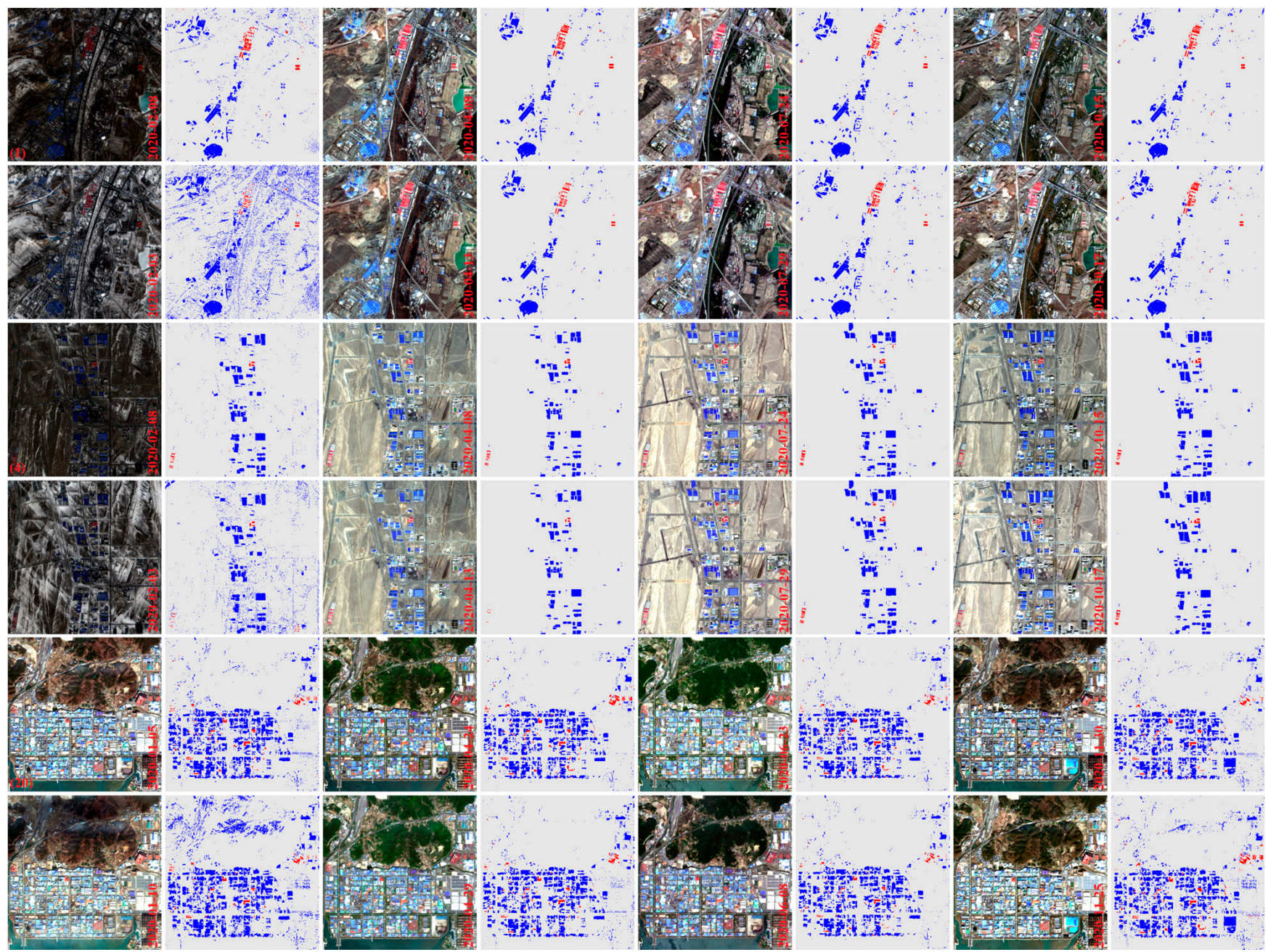

Figure 9. RGB images (columns 1, 3, 5 and 7) and detected results by LBBI and LRBI (columns 2, 4, 6 and 8) using Sentinel-2A (rows 1, 3 and 5) and Sentinel-2B (rows 2, 4 and 6) on four seasons (red numbers at the lower-left corner correspond to site numbers in Table 1, red numbers at the lower right corner represent the sensing day).

According to the results in Figure 10, the top three areas for blue CCSS roofs are the provinces of Shandong $\left(1.99 \times 10^{9} \mathrm{~m}^{2}\right)$, Henan $\left(1.52 \times 10^{9} \mathrm{~m}^{2}\right)$, and Jiangsu $\left(1.45 \times 10^{9} \mathrm{~m}^{2}\right)$, which account in total for approximately $30 \%$ of the blue CCSS covered buildings in China. The top three areas for red CCSS roofs are instead the provinces of Hebei $\left(1.38 \times 10^{8} \mathrm{~m}^{2}\right)$, Heilongjiang $\left(9.46 \times 10^{8} \mathrm{~m}^{2}\right)$, and Inner Mongolia $\left(7.55 \times 10^{9} \mathrm{~m}^{2}\right)$, which together account for approximately $38 \%$ of this type of roof in China. By comparing the total areas of blue and red roofs, it can be seen that red roofs are much less common than blue ones. Moreover, in accordance with the results in Figures 10 and 11, blue CCSS roofs are more common in the central and northern provinces, such as Shandong, Henan, Jiangsu, Heilongjiang, Liaoning, and Inner Mongolia, than in the western and southwestern provinces, such as Qinghai, Ningxia, and Xizang. On the contrary, red CCSS roofs are more common in northern provinces. This is because the red CCSS roofs have better thermal capacity than blue roofs; hence, they have a higher use rate in provinces with a colder climate. 


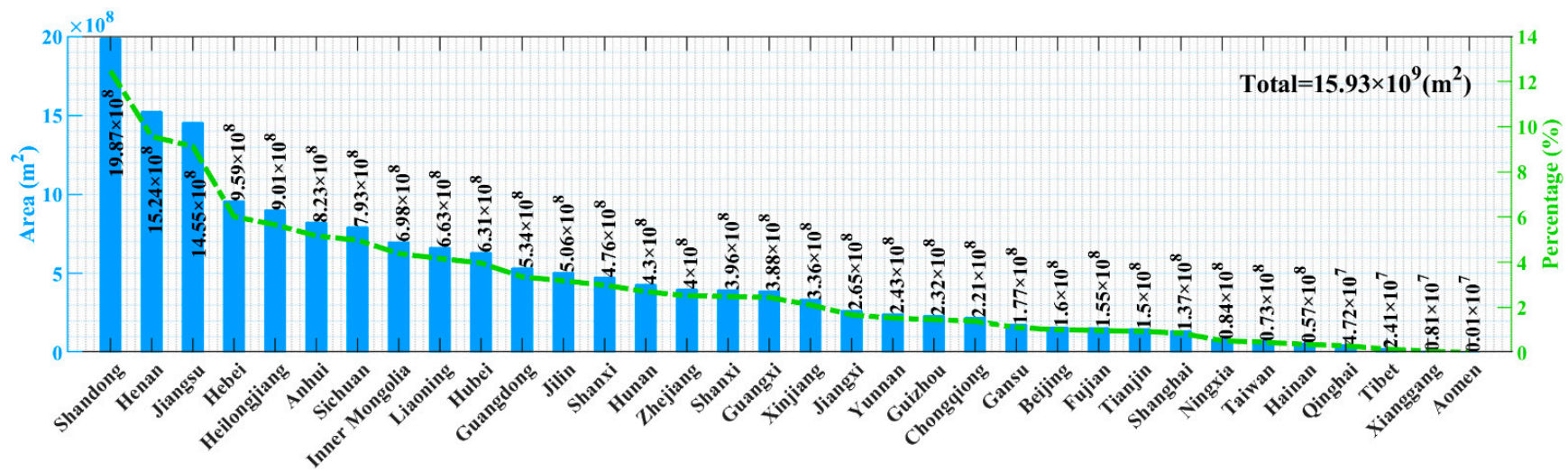

(a)

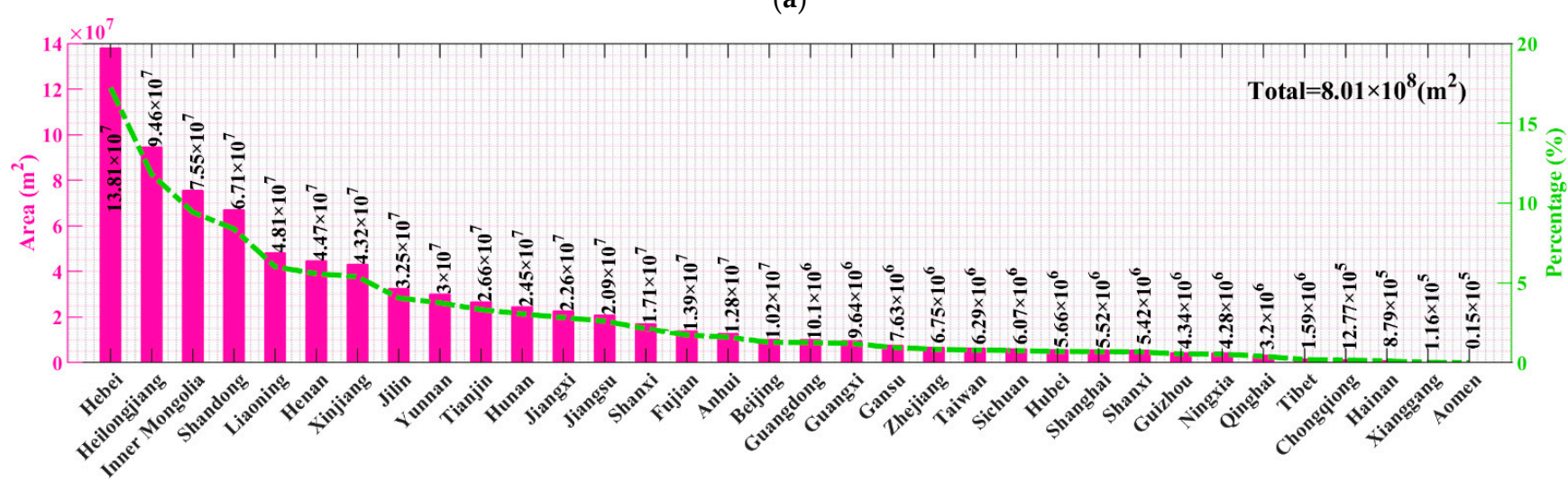

(b)

Figure 10. Area in square meters $\left(\mathrm{m}^{2}\right)$ and proportion in percentage of blue (a) and red (b) CCSS roof buildings for provincial-level administrative areas of China in 2020.

As a final analysis, the total area of blue and red CCSS roofs was used to investigate its correlation with a few socio-economic factors. In line with the previous results, and as shown in Figure 11d-f, the northern provinces of Heilongjiang and Inner Mongolia have the highest per capita area of both blue and red CCSS roofs, while the lowest per capita area of these roofs are shown by the southern administrative areas of Guangdong, Hongkong, Fujian, and Taiwan. As for the proportion of the area of blue and red CCSS roofs to the urban extent, the largest ratio (between $6 \%$ and $7 \%$ ) is held by the southwestern provinces of Sichuan, Chongqing, Inner Mongolia, and Guizhou, while the lowest percentage (between $2 \%$ and $3 \%$ ) refers to the Fujian province on the southeast coast. Finally, according to the graded maps shown in Figure 11e, northern provinces such as Henan, Shandong, Hebei, Shanxi, Inner Mongolia, Jilin, and Heilongjiang show the lowest value of GDP per area of blue and red CCSS roofs, while the highest values pertain to Taiwan, Hongkong, Fujian, Shanghai, and Beijing. Further comparing the linear logistic regression charts in the uppermiddle parts of Figure 11d-f, we can see that the total area of blue and red CCSS roofs has a weakly significant positive correlation with the population numbers (R2 = 0.5445), a strong correlation with the urban areas' size $(\mathrm{R} 2=0.9063)$ and a not enough significant correlation with the GDP $(\mathrm{R} 2=0.316)$. 

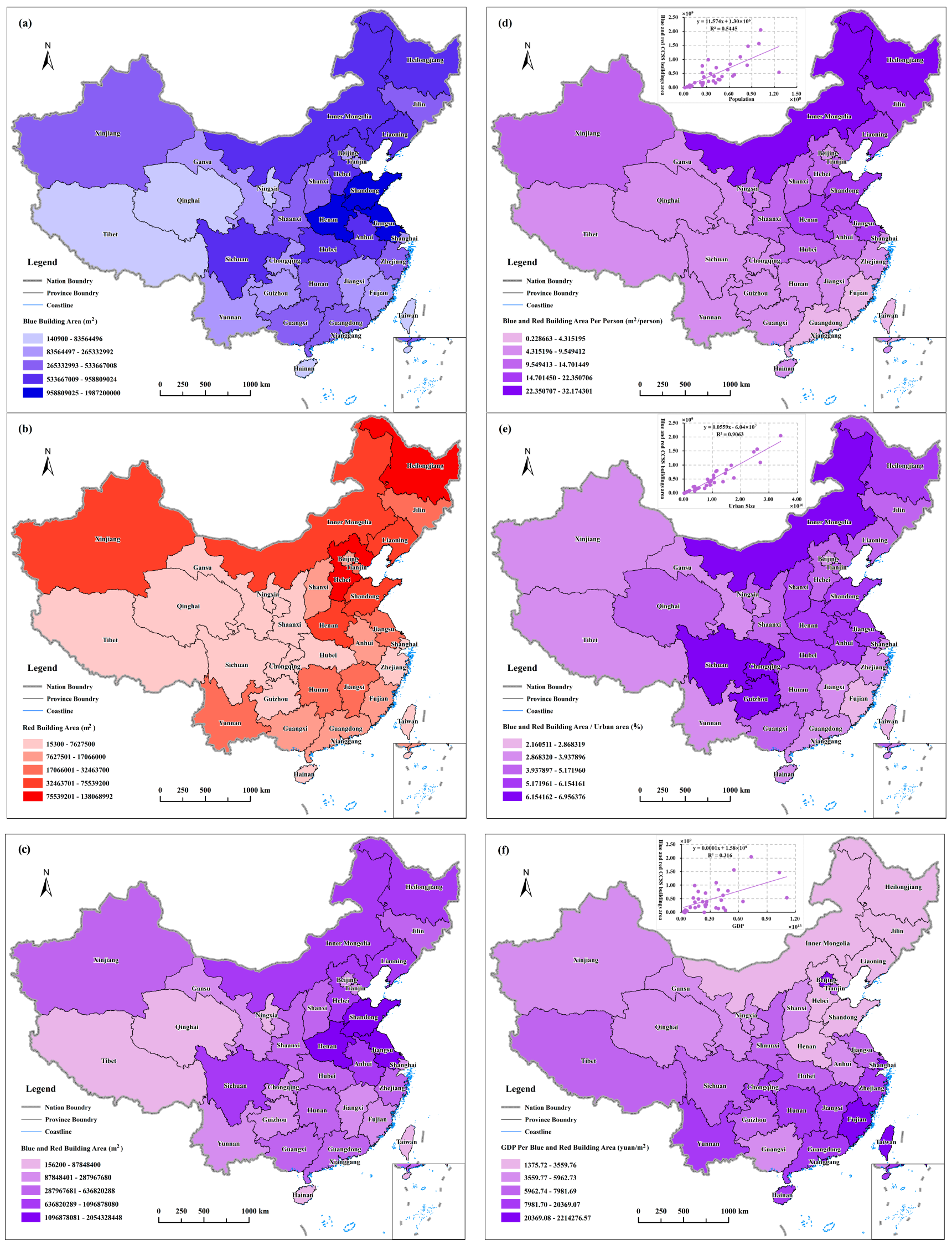

Figure 11. Graded maps for areas of blue (a), red (b), and blue plus red (c) CCSS roof buildings and their relations to population (d), urban size (e), and GDP (f) for provincial-level administrative areas of China in 2020. 


\section{Conclusions}

In this study, six novel spectral indexes, namely the NDBBI, NDRBI, EBBI, ERBI, LBBI, and LRBI indexes, are proposed for the recognition of blue and red color-coated steel sheet (CCSS) materials. They exploit Sentinel-2A/B MSIL2A data to enhance, detect and extract CCSS roofs in urban areas. NDBBI, NDRBI, EBBI, and ERBI were evaluated in several dense urban area sites by visually comparing them with the existing indexes RI and BI, while LBBI and LRBI were evaluated in 32 urban sites in Asia and Africa by comparing their roof detection results with those by a supervised classification technique, namely OCSVM. Finally, distribution patterns of CCSS roofs, as well as their total, were analyzed area. Relations to a few socio-economic factors at the province level for the whole of China were explored, too. The results demonstrate that NDBBI, NDRBI, EBBI, and ERBI are capable of visually enhancing the blue and red CCSS roofs and that LBBI and LRBI are capable of effectively extracting them.

Moreover, blue and red CCSS roofs are mainly distributed in the northern provinces of China and have an obvious positive correlation with population numbers and the urban area size. Future works will explore how to extend NDBBI, NDRBI, EBBI, ERBI, LBBI, and LRBI for the Landsat 8 operational land imager (OLI) and the Chinese Gaofen and Ziyuan sensors. Additionally, multi-temporal patterns of blue and red CCSS roofs are expected to provide in the future more interesting relations with other socio-economic factors.

Author Contributions: Conceptualization, A.S. and P.G.; methodology, A.S.; validation, W.W., J.L. and E.L.; formal analysis, A.S. and P.G.; investigation, A.S.; data curation, W.W; writing-original draft preparation, A.S.; writing-review and editing, A.S. and P.G; visualization, A.S.; supervision, S.L., P.D. and J.A.; funding acquisition, A.S. All authors have read and agreed to the published version of the manuscript.

Funding: This work was partially supported by the National Natural Science Foundation of China (No. 42071424), the Youth Innovation Promotion Association Foundation of the Chinese Academy of Sciences (No.2018476).

Institutional Review Board Statement: Not applicable.

Informed Consent Statement: Not applicable.

Data Availability Statement: GCL-FCS30-2020 product used in this work is available at: https:/ / data.casearth.cn/sdo/detail/5d904b7a0887164a5c7fbfa0 (13 January 2021); GLS-S2Net-2018 product used in this work is available at: https: / code.earthengine.google.com/6a1457205bd295a44902a6c2 eb266204?hideCode=true (26 March 2021); provincial-level population and GDP income data used in this work are available from the National Bureau of Statistics at http:/ / www.stats.gov.cn/tjsj/ndsj/ (25 April 2021).

Acknowledgments: We would like to thank Liu Liangyun from the Aerospace Information Research Institute, Chinese Academy of Sciences for providing the global land cover with fine classification system at $30 \mathrm{~m}$ in 2020 product (GCL-FCS30-2020). We also would like to thank Christina Corbane from the European Commission, Joint Research Centre (JRC) for providing Global Human Settlements from Sentinel-2 satellite imagery using convolutional neural networks (GLS-S2Net-2018) product used in this study.

Conflicts of Interest: The authors declare no conflict of interest.

\section{References}

1. Chen, G.; Li, X.; Liu, X.; Chen, Y.; Liang, X.; Leng, J.; Xu, X.; Liao, W.; Qiu, Y.; Wu, Q.; et al. Global projections of future urban land expansion under shared socioeconomic pathways. Nat. Commun. 2020, 11, 1-12. [CrossRef]

2. United Nations. World Urbanization Prospects: The 2018 Revision; United Nations Department of Economic and Social Affairs, Population Division: New York, NY, USA, 2018.

3. United Nations. World Population Prospects: The 2017 Revision; United Nations Department of Economic and Social Affairs, Population Division: New York, NY, USA, 2017.

4. Zhou, Y.; Li, X.; Asrar, G.R.; Smith, S.J.; Imhoff, M. A global record of annual urban dynamics (1992-2013) from nighttime lights. Remote Sens. Environ. 2018, 219, 206-220. [CrossRef] 
5. Gong, P.; Li, X.; Wang, J.; Bai, Y.; Chen, B.; Hu, T.; Liu, X.; Xu, B.; Yang, J.; Zhang, W.; et al. Annual maps of global artificial impervious area (GAIA) between 1985 and 2018. Remote Sens. Environ. 2020, 236, 111510. [CrossRef]

6. Li, X.; Zhou, Y.; Eom, J.; Yu, S.; Asrar, G.R. Projecting global urban area growth through 2100 based on historical time series data and future Shared Socioeconomic Pathways. Earths Future 2019, 7, 351-362. [CrossRef]

7. Govindan, K.; Shankar, K.M.; Kannan, D. Sustainable material selection for construction industry-A hybrid multi criteria decision making approach. Renew. Sustain. Energy Rev. 2016, 55, 1274-1288. [CrossRef]

8. Chauvin, J.P.; Glaeser, E.; Ma, Y.; Tobio, K. What is different about urbanization in rich and poor countries? Cities in Brazil, China, India and the United States. J. Urban Econ. 2017, 98, 17-49. [CrossRef]

9. Wang, L.; Wang, S.; Zhou, Y.; Liu, W.; Hou, Y.; Zhu, J.; Wang, F. Mapping population density in China between 1990 and 2010 using remote sensing. Remote Sens. Environ. 2018, 210, 269-281. [CrossRef]

10. Zhang, W.; Li, W.; Zhang, C.; Hanink, D.M.; Liu, Y.; Zhai, R. Analyzing horizontal and vertical urban expansions in three East Asian megacities with the SS-coMCRF model. Landsc. Urban Plan. 2018, 177, 114-127. [CrossRef]

11. Fan, P.; Ouyang, Z.; Nguyen, D.D.; Nguyen, T.T.H.; Park, H.; Chen, J. Urbanization, economic development, environmental and social changes in transitional economies: Vietnam after Doimoi. Landsc. Urban Plan. 2019, 187, 145-155. [CrossRef]

12. Grimm, N.B.; Faeth, S.H.; Golubiewski, N.E.; Redman, C.L.; Wu, J.G.; Bai, X.M.; Briggs, J.M. Global change and the ecology of cities. Science 2008, 319, 756-760. [CrossRef]

13. Seto, K.C.; Satterthwaite, D. Interactions between urbanization and global environmental change. Curr. Opin. Environ. Sustain. 2010, 2, 127-128. [CrossRef]

14. Imhoff, M.L.; Zhang, P.; Wolfe, R.E.; Bounoua, L. Remote sensing of the urban heat island effect across biomes in the continental USA. Remote Sens. Environ. 2010, 114, 504-513. [CrossRef]

15. Zhou, D.; Zhao, S.; Zhang, L.; Liu, S. Remotely sensed assessment of urbanization effects on vegetation phenology in China's 32 major cities. Remote Sens. Environ. 2016, 176, 272-281. [CrossRef]

16. He, C.; Gao, B.; Huang, Q.; Ma, Q.; Dou, Y. Environmental degradation in the urban areas of China: Evidence from multi-source remote sensing data. Remote Sens. Environ. 2017, 193, 65-75. [CrossRef]

17. Amaya-Espinel, J.D.; Hostetler, M.; Henríquez, C.; Bonacic, C. The influence of building density on Neotropical bird communities found in small urban parks. Landsc. Urban Plan. 2019, 190, 103578. [CrossRef]

18. Yu, Z.; Yao, Y.; Yang, G.; Wang, X.; Vejre, H. Strong contribution of rapid urbanization and urban agglomeration development to regional thermal environment dynamics and evolution. For. Ecol. Manag. 2019, 446, 214-225. [CrossRef]

19. Wang, Y.; Li, M. Urban Impervious Surface Detection from Remote Sensing Images: A review of the methods and challenges. IEEE Geosci. Remote Sens. Mag. 2019, 7, 64-93. [CrossRef]

20. Zhong, Q.; Ma, J.; Zhao, B.; Wang, X.; Zong, J.; Xiao, X. Assessing spatial-temporal dynamics of urban expansion, vegetation greenness and photosynthesis in megacity Shanghai, China during 2000-2016. Remote Sens. Environ. 2019, 233, 111374. [CrossRef]

21. Qiu, T.; Song, C.; Zhang, Y.; Liu, H.; Vose, J.M. Urbanization and climate change jointly shift land surface phenology in the northern mid-latitude large cities. Remote Sens. Environ. 2020, 236, 111477. [CrossRef]

22. Schneider, A.; Friedl, M.A.; Potere, D. Mapping global urban areas using MODIS 500-m data: New methods and datasets based on 'urban ecoregions'. Remote Sens. Environ. 2010, 114, 1733-1746. [CrossRef]

23. Liu, X.; Hu, G.; Chen, Y.; Li, X.; Xu, X.; Li, S.; Pei, F.; Wang, S. High-resolution multi-temporal mapping of global urban land using Landsat images based on the Google Earth Engine Platform. Remote Sens. Environ. 2018, 209, 227-239. [CrossRef]

24. Taubenböck, H.; Roth, A.; Esch, T.; Felbier, A.; Müller, A.; Dech, S. The vision of mapping the global urban footprint using the TerraSAR-X and TanDEM-X mission. In Urban and Regional Data Management; CRC Press: Boca Raton, FL, USA, $2011 ;$ pp. $243-251$.

25. Esch, T.; Heldens, W.; Hirner, A.; Keil, M.; Marconcini, M.; Roth, A.; Zeidler, J.; Dech, S.; Strano, E. Breaking new ground in mapping human settlements from space-The Global Urban Footprint. ISPRS J. Photogramm. Remote Sens. 2017, 134, 30-42. [CrossRef]

26. Sharma, R.C.; Tateishi, R.; Hara, K.; Gharechelou, S.; Iizuka, K. Global mapping of urban built-up areas of year 2014 by combining MODIS multispectral data with VIIRS nighttime light data. Int. J. Digit. Earth 2016, 9, 1004-1020. [CrossRef]

27. Sinha, P.; Verma, N.K.; Ayele, E. Urban built-up area extraction and change detection of Adama municipal area using time-series Landsat images. Int. J. Adv. Remote Sens. GIS 2016, 5, 1886-1895. [CrossRef]

28. Ma, X.; Li, C.; Tong, X.; Liu, S. A New Fusion Approach for Extracting Urban Built-up Areas from Multisource Remotely Sensed Data. Remote Sens. 2019, 11, 2516. [CrossRef]

29. Zhang, L.; Weng, Q.; Shao, Z. An evaluation of monthly impervious surface dynamics by fusing Landsat and MODIS time series in the Pearl River Delta, China, from 2000 to 2015. Remote Sens. Environ. 2017, 201, 99-114. [CrossRef]

30. Deng, C.; Zhu, Z. Continuous subpixel monitoring of urban impervious surface using Landsat time series. Remote Sens. Environ. 2018, 238, 110929. [CrossRef]

31. Shi, K.; Huang, C.; Yu, B.; Yin, B.; Huang, Y.; Wu, J. Evaluation of NPP-VIIRS night-time light composite data for extracting built-up urban areas. Remote Sens. Lett. 2014, 5, 358-366. [CrossRef]

32. Che, M.; Gamba, P. Intra-urban change analysis using Sentinel-1 and Nighttime Light Data. IEEE J. Sel. Top. Appl. Earth Obs. Remote Sens. 2019, 12, 1134-1142. [CrossRef]

33. Chen, Z.; Yu, B.; Zhou, Y.; Liu, H.; Yang, C.; Shi, K.; Wu, J. Mapping global urban areas from 2000 to 2012 using time-series nighttime light data and MODIS products. IEEE J. Sel. Top. Appl. Earth Obs. Remote Sens. 2019, 12, 1143-1153. [CrossRef] 
34. Chrysoulakis, N.; Grimmond, S.; Feigenwinter, C.; Lindberg, F.; Gastellu-Etchegorry, J.P.; Marconcini, M.; Mitraka, Z.; Stagakis, S.; Crawford, B.; Olofson, F.; et al. Urban energy exchanges monitoring from space. Sci. Rep. 2018, 8, 1-8.

35. Huang, X.; Wang, Y. Investigating the effects of 3D urban morphology on the surface urban heat island effect in urban functional zones by using high-resolution remote sensing data: A case study of Wuhan, Central China. ISPRS J. Photogramm. Remote Sens. 2019, 152, 119-131. [CrossRef]

36. Kantakumar, L.N.; Kumar, S.; Schneider, K. SUSM: A scenario-based urban growth simulation model using remote sensing data. Eur. J. Remote Sens. 2019, 52 (Suppl. S2), 26-41. [CrossRef]

37. Gao, J.; O'Neill, B.C. Mapping global urban land for the 21st century with data-driven simulations and Shared Socioeconomic Pathways. Nat. Commun. 2020, 11, 1-12. [CrossRef]

38. Davidson, F. Planning for performance: Requirements for sustainable development. Habitat Int. 1996, 20, 445-462. [CrossRef]

39. Colding, J. 'Ecological land-use complementation' for building resilience in urban ecosystems. Landsc. Urban Plan. 2007, 81, 46-55. [CrossRef]

40. Van der Linden, S.; Hostert, P. The influence of urban structures on impervious surface maps from airborne hyperspectral data. Remote Sens. Environ. 2009, 113, 2298-2305. [CrossRef]

41. Peng, J.; Xie, P.; Liu, Y.; Ma, J. Urban thermal environment dynamics and associated landscape pattern factors: A case study in the Beijing metropolitan region. Remote Sens. Environ. 2016, 173, 145-155. [CrossRef]

42. Meng, Q.; Zhang, L.; Sun, Z.; Meng, F.; Wang, L.; Sun, Y. Characterizing spatial and temporal trends of surface urban heat island effect in an urban main built-up area: A 12-year case study in Beijing, China. Remote Sens. Environ. 2018, 204, 826-837. [CrossRef]

43. Kobetičová, K.; Černý, R. Terrestrial eutrophication of building materials and buildings: An emerging topic in environmental studies. Sci. Total Environ. 2019, 689, 1316-1328. [CrossRef]

44. Kanniyapan, G.; Nesan, L.J.; Mohammad, I.S.; Tan, S.K.; Ponniah, V. Selection criteria of building material for optimising maintainability. Constr. Build. Mater. 2019, 221, 651-660. [CrossRef]

45. Cha, G.W.; Moon, H.J.; Kim, Y.C.; Hong, W.H.; Jeon, G.Y.; Yoon, Y.R.; Hwang, C.; Hwang, J.H. Evaluating recycling potential of demolition waste considering building structure types: A study in South Korea. J. Clean. Prod. 2020, 256, 120385. [CrossRef]

46. Westermann, P.; Deb, C.; Schlueter, A.; Evins, R. Unsupervised learning of energy signatures to identify the heating system and building type using smart meter data. Appl. Energy 2020, 264, 114715. [CrossRef]

47. Mongus, D.; Lukač, N.; Žalik, B. Ground and building extraction from LiDAR data based on differential morphological profiles and locally fitted surfaces. ISPRS J. Photogramm. Remote Sens. 2014, 93, 145-156. [CrossRef]

48. Grinias, I.; Panagiotakis, C.; Tziritas, G. MRF-based segmentation and unsupervised classification for building and road detection in peri-urban areas of high-resolution satellite images. ISPRS J. Photogramm. Remote Sens. 2016, 122, 145-166. [CrossRef]

49. Du, S.; Luo, L.; Cao, K.; Shu, M. Extracting building patterns with multilevel graph partition and building grouping. ISPRS J. Photogramm. Remote Sens. 2016, 122, 81-96. [CrossRef]

50. He, X.; Zhang, X.; Xin, Q. Recognition of building group patterns in topographic maps based on graph partitioning and random forest. ISPRS J. Photogramm. Remote Sens. 2018, 136, 26-40. [CrossRef]

51. Huang, J.; Zhang, X.; Xin, Q.; Sun, Y.; Zhang, P. Automatic building extraction from high-resolution aerial images and LiDAR data using gated residual refinement network. ISPRS J. Photogramm. Remote Sens. 2019, 151, 91-105. [CrossRef]

52. Shi, Y.; Li, Q.; Zhu, X.X. Building segmentation through a gated graph convolutional neural network with deep structured feature embedding. ISPRS J. Photogramm. Remote Sens. 2020, 159, 184-197. [CrossRef]

53. Rodríguez-Álvarez, J. Urban Energy Index for Buildings (UEIB): A new method to evaluate the effect of urban form on buildings' energy demand. Landsc. Urban Plan. 2016, 148, 170-187. [CrossRef]

54. Custódio, J.V.; Agostinho, S.M.; Simões, A.M. Electrochemistry and surface analysis of the effect of benzotriazole on the cut edge corrosion of galvanized steel. Electrochim. Acta 2010, 55, 5523-5531. [CrossRef]

55. Hernández-Pérez, I.; Zavala-Guillén, I.; Xamán, J.; Belman-Flores, J.M.; Macias-Melo, E.V.; Aguilar-Castro, K.M. Test box experiment to assess the impact of waterproofing materials on the energy gain of building roofs in Mexico. Energy 2019, 186, 115847. [CrossRef]

56. Torres-Quezada, J.; Coch, H.; Isalgué, A. Assessment of the reflectivity and emissivity impact on light metal roofs thermal behaviour, in warm and humid climate. Energy Build. 2019, 188, 200-208. [CrossRef]

57. Hu, J.; Chen, W.; Qu, Y.; Yang, D. Safety and serviceability of membrane buildings: A critical review on architectural, material and structural performance. Eng. Struct. 2020, 210, 110292. [CrossRef]

58. Lee, C.Y.; Kaneko, S.; Sharifi, A. Effects of building types and materials on household electricity consumption in Indonesia. Sustain. Cities Soc. 2020, 54, 101999. [CrossRef]

59. Xamán, J.; Rodriguez-Ake, A.; Zavala-Guillén, I.; Hernández-Pérez, I.; Arce, J.; Sauceda, D. Thermal performance analysis of a roof with a PCM-layer under Mexican weather conditions. Renew. Energy 2020, 149, 773-785. [CrossRef]

60. Xie, S.; Ji, Z.; Zhu, L.; Zhang, J.; Cao, Y.; Chen, J.; Liu, R.; Wang, J. Recent progress in electromagnetic wave absorption building materials. J. Build. Eng. 2020, 27, 100963. [CrossRef]

61. Heiden, U.; Segl, K.; Roessner, S.; Kaufmann, H. Determination of robust spectral features for identification of urban surface materials in hyperspectral remote sensing data. Remote Sens. Environ. 2007, 111, 537-552. [CrossRef]

62. Chisense, C.; Hahn, M.; Engels, J. Classification of roof materials using hyperspectral data. International Archives of the Photogrammetry. Remote Sens. Spat. Inf. Sci. 2012, 39, 103. 
63. Yuan, L.; Guo, J.; Wang, Q. Automatic classification of common building materials from 3D terrestrial laser scan data. Autom. Constr. 2020, 110, 103017. [CrossRef]

64. Guo, X.; Li, P. Mapping plastic materials in an urban area: Development of the normalized difference plastic index using WorldView-3 superspectral data. ISPRS J. Photogramm. Remote Sens. 2020, 169, 214-216. [CrossRef]

65. Wang, J.; Yang, W.; Yang, S.; Yan, H. Spatial Distribution Characteristics of Color Steel Plate Buildings in Lanzhou City; Modern Environmental Science and Engineering: Brooklyn, NY, USA, 2019; p. 583.

66. Wang, J.; Yang, W.; Yang, S.; Ma, J. Research on spatial distribution characteristics of color steel buildings in Anniing district of Lanzhou. J. Lanzhou Jiaotong Univ. 2019, 38, 110-114.

67. Yu, B.; Liu, H.; Wu, J.; Hu, Y.; Zhang, L. Automated derivation of urban building density information using airborne LiDAR data and object-based method. Landsc. Urban Plan. 2010, 98, 210-219. [CrossRef]

68. Zhang, T.; Huang, X.; Wen, D.; Li, J. Urban building density estimation from high-resolution imagery using multiple features and support vector regression. IEEE J. Sel. Top. Appl. Earth Obs. Remote Sens. 2017, 10, 3265-3280. [CrossRef]

69. Maltezos, E.; Doulamis, A.; Doulamis, N.; Ioannidis, C. Building extraction from LiDAR data applying deep convolutional neural networks. IEEE Geosci. Remote Sens. Lett. 2018, 16, 155-159. [CrossRef]

70. Brunner, D.; Lemoine, G.; Bruzzone, L.; Greidanus, H. Building height retrieval from VHR SAR imagery based on an iterative simulation and matching technique. IEEE Trans. Geosci. Remote Sens. 2009, 48, 1487-1504. [CrossRef]

71. Nie, X.; Qiao, H.; Zhang, B. A variational model for PolSAR data speckle reduction based on the Wishart distribution. IEEE Trans. Image Processing 2015, 24, 1209-1222.

72. Zheng, J.; Zeng, C.; Zhang, H. Scattering Modeling of Urban Oriented Buildings in PolSAR images by Using Adaptive Statistical Distribution. IEEE Access 2019, 7, 147119-147128. [CrossRef]

73. Gorelick, N.; Hancher, M.; Dixon, M.; Ilyushchenko, S.; Thau, D.; Moore, R. Google Earth Engine: Planetary-scale geospatial analysis for everyone. Remote Sens. Environ. 2017, 202, 18-27. [CrossRef]

74. Kumar, L.; Mutanga, O. Google Earth Engine applications since inception: Usage, trends, and potential. Remote Sens. 2018, 10, 1509. [CrossRef]

75. Tamiminia, H.; Salehi, B.; Mahdianpari, M.; Quackenbush, L.; Adeli, S.; Brisco, B. Google Earth Engine for geo-big data applications: A meta-analysis and systematic review. ISPRS J. Photogramm. Remote Sens. 2020, 164, 152-170. [CrossRef]

76. Amani, M.; Ghorbanian, A.; Ahmadi, S.A.; Kakooei, M.; Moghimi, A.; Mirmazloumi, S.M.; Moghaddam, S.H.A.; Mahdavi, S.; Ghahremanloo, M.; Parsian, S.; et al. Google earth engine cloud computing platform for remote sensing big data applications: A comprehensive review. IEEE J. Sel. Top. Appl. Earth Obs. Remote Sens. 2020, 13, 5326-5350. [CrossRef]

77. Wang, L.; Diao, C.; Xian, G.; Yin, D.; Lu, Y.; Zou, S.; Erickson, T.A. A summary of the special issue on remote sensing of land change science with Google earth engine. Remote Sens. Environ. 2020, 248, 112002. [CrossRef]

78. Wang, W.; Samat, A.; Ge, Y.; Ma, L.; Tuheti, A.; Zou, S.; Abuduwaili, J. Quantitative soil wind erosion potential mapping for Central Asia using the Google Earth Engine platform. Remote Sens. 2020, 12, 3430. [CrossRef]

79. Zhao, Q.; Yu, L.; Li, X.; Peng, D.; Zhang, Y.; Gong, P. Progress and Trends in the Application of Google Earth and Google Earth Engine. Remote Sens. 2021, 13, 3778. [CrossRef]

80. Fan, S.; Sun, C. Production Technology for Colour Coated Steel Sheet. Angang Technol. 2004, 4, 1.

81. Annual Research and Consultation Report of Panorama Survey and Investment Strategy on China Strategy. Available online: https:/ / www.chinairn.com/report/20210526.html (accessed on 25 April 2021).

82. Ma, J.; Yang, S.; Jia, X.; Yan, R. Temporal and spatial change of color steel sheds in Anning district of Lanzhou city. Sci. Surv. Mapp. 2018, 43, 34-37.

83. Wang, S.; Ju, W.; Peñuelas, J.; Cescatti, A.; Zhou, Y.; Fu, Y.; Huete, A.; Liu, M.; Zhang, Y. Urban- rural gradients reveal joint control of elevated CO2 and temperature on extended photosynthetic seasons. Nat. Ecol. Evol. 2019, 3, 1076-1085. [CrossRef]

84. Chen, Z.S.; Martínez, L.; Chang, J.P.; Wang, X.J.; Xionge, S.H.; Chin, K.S. Sustainable building material selection: A QFD-and ELECTRE III-embedded hybrid MCGDM approach with consensus building. Eng. Appl. Artif. Intell. 2019, 85, 783-807. [CrossRef]

85. Martin Schaefer, H.; Schaefer, V.; Vorobyev, M. Are fruit colors adapted to consumer vision and birds equally efficient in detecting colorful signals? Am. Nat. 2007, 169, S159-S169. [CrossRef]

86. Robb, M.J.; Ku, S.Y.; Brunetti, F.G.; Hawker, C.J. A renaissance of color: New structures and building blocks for organic electronics. J. Polym. Sci. Part A Polym. Chem. 2013, 51, 1263-1271. [CrossRef]

87. Ren, J.; Liang, H.; Chan, F.T. Urban sewage sludge, sustainability, and transition for Eco-City: Multi-criteria sustainability assessment of technologies based on best-worst method. Technol. Forecast. Soc. Change 2017, 116, 29-39. [CrossRef]

88. Leveau, L.M. Urbanization induces bird color homogenization. Landsc. Urban Plan. 2019, 192, 103645. [CrossRef]

89. Li, P.; Yang, S.; Yao, H.; Yang, M.; Yong, W. Research on Extraction of the Urban Color Steel Shed Based on High-resolution Remote Sensing Images. Geospat. Inf. 2017, 15, 13-18.

90. Ye, C.M.; Cui, P.; Pirasteh, S.; Li, J.; Li, Y. Experimental approach for identifying building surface materials based on hyperspectral remote sensing imagery. J. Zhejiang Univ.-Sci. A 2017, 18, 984-990. [CrossRef]

91. Drusch, M.; Del Bello, U.; Carlier, S.; Colin, O.; Fernandez, V.; Gascon, F.; Hoersch, B.; Isola, C.; Laberinti, P.; Martimort, P.; et al. Sentinel-2: ESA's optical high-resolution mission for GMES operational services. Remote Sens. Environ. 2012, 120, 25-36. [CrossRef] 
92. Zhang, X.; Liu, L.; Chen, X.; Gao, Y.; Xie, S.; Mi, J. GLC_FCS30: Global land-cover product with fine classification system at $30 \mathrm{~m}$ using time-series Landsat imagery. Earth Syst. Sci. Data 2021, 13, 2753-2776. [CrossRef]

93. Corbane, C.; Syrris, V.; Sabo, F.; Politis, P.; Melchiorri, M.; Pesaresi, M.; Soille, P.; Kemper, T. Convolutional neural networks for global human settlements mapping from Sentinel-2 satellite imagery. Neural Comput. Appl. 2021, 33, 6697-6720. [CrossRef]

94. Chen, J.; Jönsson, P.; Tamura, M.; Gu, Z.; Matsushita, B.; Eklundh, L. A simple method for reconstructing a high-quality NDVI time-series data set based on the Savitzky-Golay filter. Remote Sens. Environ. 2004, 91, 332-344. [CrossRef]

95. Babaei, H.; Janalipour, M.; Tehrani, N.A. A simple, robust, and automatic approach to extract water body from Landsat images (case study: Lake Urmia, Iran). J. Water Clim. Change 2021, 12, 238-249. [CrossRef]

96. Escadafal, R. Remote sensing of soil color: Principles and applications. Remote Sens. Rev. 1993, 7, 261-279. [CrossRef]

97. Chang, C.C.; Lin, C.J. LIBSVM: A library for support vector machines. ACM Trans. Intell. Syst. Technol. (TIST) $2011,2,1-27$. [CrossRef]

98. Maussang, F.; Chanussot, J.; Hetet, A. Automated segmentation of SAS images using the mean-standard deviation plane for the detection of underwater mines. In Proceedings of the Oceans 2003. Celebrating the Past ... Teaming Toward the Future (IEEE Cat. No.03CH37492), San Diego, CA, USA, 22-26 September 2003; Volume 4, pp. 2155-2160. 